\title{
FORCES THAT SHAPE THE YIELD CURVE: PARTS 1 AND 2
}

\author{
MARK FISHER
}

\begin{abstract}
The yield curve is shaped by $(i)$ expectations of the future path of short-term interest rates and $(i i)$ uncertainty about the path. Uncertainty affects the yield curve through two channels: $(i)$ Investors attitudes toward risk as reflected in risk premia, and $(i i)$ the nonlinear relation between yields and bond prices (known as convexity). The way in which these forces simultaneously work to shape the yield curve can be understood in terms of the conditions that guarantee the absence of arbitrage opportunities.
\end{abstract}

\section{PuRpose AND OUTLINE}

The purpose of the paper is to provide an introduction to the modern theory of the term structure of interest rates using high-school algebra. ${ }^{1}$ In order to present the theory correctly, we must take uncertainty seriously. Nevertheless, the source of uncertainty can be modeled quite simply: All uncertainty is resolved by a single flip of a coin. In this setting, we can rigorously present all three forces that shape the yield curve: expectations, risk aversion, and convexity. The analysis is organized around the conditions that guarantee the absence of arbitrage opportunities.

The paper is divided into two parts. Part 1 presents material that was largely incorporated into a Review article. ${ }^{2}$ Part 2 completes the analysis, providing material beyond the scope of the Review article.

Part 1 begins with an introductory section in which the basic ideas are first developed by the use of an analogy. Next, bond pricing is introduced in a world of perfect certainty, where no-arbitrage conditions are first worked out algebraically. (In this setting, the absence-of-arbitrage conditions are equivalent to the expectations hypothesis of the term structure of interest rates.) Next, uncertainty is introduced via the coin flip, and the no-arbitrage conditions for bond prices are worked out again. These no-arbitrage conditions are shown to imply the existence of a risk premium

Date: March 1, 2001.

Some of the material is based on a memo written at the Federal Reserve Board co-authored with Christian Gilles. The observation that the taxable-tax-exempt spread is affected by convexity is due to Joel Lander. I have received helpful comments on an earlier draft from Lucy Ackert, Christian Gilles, Frank King, Steve LeRoy, Saikat Nandi, Steve Smith, and Larry Wall. The views expressed herein are the author's and do not necessarily reflect those of the Federal Reserve Bank of Atlanta or the Federal Reserve System.

${ }^{1}$ Beginning in Section 5, exponentials and logs are used heavily, including hyperbolic sines and cosines. Calculus appears only occasionally in footnotes.

${ }^{2}$ See Fisher (2001). 
that depends the price of risk, which is common to all bonds, and the amount of risk as measured by the volatility of a bond's price. (This implication is the central message of the paper. ${ }^{3}$ ) The following section, which ends Part 1, translates (at least in part) the no-arbitrage condition for bond prices into a no-arbitrage condition for yields. The nonlinearity of the price-yield relation brings the convexity term into play.

Part 2 begins with a section that completes the translation of no-arbitrage conditions in terms of yields. The next section completes the central analysis by embedding the source of uncertainty into the interest rate itself. The analysis is then applied in the next section to the expectations hypothesis, according to which the expected future interest rate equals the forward rate. In the final section, the power of the analysis is illustrated by showing how uncertainty affects the spread between taxable and tax-exempt yields. In Appendix A, the analysis is restated in terms of the stochastic discount factor. In Appendix B, adjusted probabilities (also known as risk-neutral probabilities) are introduced. In Appendix C, the analysis is extended to two sources of uncertainty (two coin flips).

\section{Part 1. Largely duplicated by the Review article}

\section{INTRODUCTION}

Monetary policy makers and observers pay special attention to the shape of the yield curve as an indicator of the impact of current and future monetary policy on the economy. However, drawing inferences from the yield curve is much like reading tea leaves if one does not have the proper tools for yield-curve analysis. The purpose of this paper is to provide a rigorous yet accessible introduction to those tools.

What is the yield curve? The simplest kind of bond is called a zero-coupon bond. A zero-coupon bond (also known as a discount bond) makes a single payment on its maturity date. By contrast, a coupon bond makes periodic interest payments (called coupon payments) prior to its maturity when it also makes a final payment that represents repayment of principal. A coupon bond may be thought of as a portfolio of zero-coupon bonds.

A default-free bond is a bond for which all of the payments are certain to be made in full and on time. U.S. Treasury securities are generally considered to be defaultfree. The Treasury issues both coupon bonds and zero-coupon bonds. Treasury bills are zero-coupon bonds with original maturities of one year of less. Treasury notes and bonds are coupon bonds with original maturities of two years or more (bonds have original maturities of twenty years or more) that pay interest twice a year. Since the mid-1980s, investors have been able to trade the coupon payments

\footnotetext{
${ }^{3}$ The implication is quite general and applies to other asset prices, not just bond prices.
} 
of certain Treasury notes and bonds separately as zero-coupon bonds in what is known as the STRIPS market. ${ }^{4}$

Bonds with different maturities typically have different yields. For example, the yield on a five-year bond is often higher than the yield on a two-year bond. But sometimes the yield on the two-year bond is higher. At any given point in time, we can plot the yield curve, which shows the relation between yields and maturity.

In order to focus on the relation between yields and maturity, we will abstract from a number of factors that can also affect a bond's yield. For example, bonds issued by private corporations or municipalities (including states and cities) are subject to credit risk, which means simply that they are not default-free. In addition, corporate and municipal bonds are not as actively traded as Treasury securities, and this illiquidity can affect their yields. Some bonds (municipal bonds in particular, but also some Treasury securities known as "flower bonds") receive special tax treatment. Many bonds (including some Treasury coupon bonds) are callable, which means the issuer has the right to buy them back at a predetermined price at some point in the future. The analysis of bond prices in this paper abstracts from all of these factors other than maturity itself. ${ }^{5}$ As such, the analysis is most directly applicable to the default-free zero-coupon bonds traded in the STRIPS market. ${ }^{6}$

The expectations hypothesis. Historically, the expectations hypothesis has been the most widely used analytical tool to understand the shape of the yield curve. ${ }^{7}$ In a nutshell, the expectations hypothesis says that the yield on long term bonds equals the average of the expected one-period interest rates. If the expectations hypothesis were correct, we could use the slope of the term structure to forecast the future path of the interest rate. For example, if the yield curve slopes upward at the short end, it would be because the interest rate is expected to rise. One problem with this version of the expectations hypothesis is that in fact the yield curve slopes upward at the short end on average, even though interest rates do not rise on average. One way to explain this divergence is to assume that investors are

\footnotetext{
${ }^{4}$ The Treasury STRIPS program was introduced in February 1985. STRIPS is the acronym for Separate Trading of Registered Interest and Principal of Securities. The STRIPS program lets investors hold and trade the individual interest and principal components of eligible Treasury notes and bonds as separate securities.

${ }^{5}$ Taxability will be treated separately below after we have analyzed the no-tax case.

${ }^{6}$ Even in the STRIPS market, there are other factors at play. Although STRIPS are subject to taxation, once we treat taxes explicitly we will see that the analysis that ignores taxes is essentially correct. It is only when we want to compare taxable bonds with tax-exempt bonds that we will need to explicitly account for the effects of taxes. Other factors are more relevant the internal structure of the STRIPS market. For technical reasons that are beyond the scope of this paper, principal-STRIPS often trade at a premium relative to the coupon-STRIPS because they implicitly contain certain options. Consequently, the analysis presented here is most applicable to coupon STRIPS.

${ }^{7}$ Actually there are a number of different but related hypotheses, each of which is called the expectations hypothesis. See Cox, Ingersoll, Jr., and Ross (1981) for a discussion of a number of these competing hypotheses. The version described here is the one most often used.
} 
simply wrong on average. ${ }^{8}$ But a good theory does not imply that investors are wrong on average.

The expectations hypothesis can be easily modified to account for this persistent upward slope in a way that does not require systematic errors on the part of investors. Since bond prices do fluctuate over time, there is uncertainty (even for default-free bonds) regarding the return from holding a long-term bond over the next period. Moreover, the amount of uncertainty increases with the maturity of the bond. If there were a risk premium associated with that uncertainty, then the yield curve could slope upward on average without implying that interest rates increase on average. If the risk premium were constant, then changes in the slope of the yield curve would forecast changes in the future path of the interest rate. For example, if the slope of the yield curve were to increase, then it must be because the path of future interest rates is expected to be higher. This increase in the slope would also imply that future bond yields would be higher. But there is a problem with this version as well.

Empirical tests of this extended version of the expectations hypothesis (using U.S. data) have shown that changes in the slope of the term structure do a poor job of forecasting changes in the bond yields. In fact, one widely-used test shows that an increase in the slope of the yield curve may actually signal a decrease in the future yields. Where did we go wrong? We went wrong by assuming that the risk premium was constant, while in fact the risk-premium varies over time. Movements in the risk premium over time are responsible for a sizeable fraction of the movements of the slope of the term structure. When risk premia increase, so does the slope even though expectations are unchanged. As a result, changes in the slope of the yield curve are often negatively correlated with changes in realized yields. ${ }^{9}$ It should be noted that the changes in the risk premia that bring about this effect can (and do) occur without any change in the risk of the bonds. Risk premia are essentially covariances that change when either the amount of risk or the price of risk changes. In a moment, we will see the effects of changing the amount of risk without changing the price of risk.

There is another feature of the yield curve that the expectations hypothesis has difficulty explaining. The zero-coupon yield curve slopes downward on average at the long end, typically over the range of twenty to thirty years. In other words, the yield on a 30-year zero-coupon bond is typically below the yield on a 20-year bond. The expectations hypothesis would suggest that this slope is due either (1)

\footnotetext{
${ }^{8}$ Another way to explain the divergence is to assume that investors give some weight to very large increases in the interest rate that we have not yet been observed. This is sometimes called the "Peso problem." See [Find Citation].

${ }^{9}$ Technical note. Let $y(t, \tau)$ be the yield at time $t$ on a zero-coupon bond that matures at time $\tau$. The classic regression that has been used to test the expectations hypothesis is

$$
\overbrace{y(t+1, t+2)-y(t, t+2)}^{\text {change in yield }}=\beta_{0}+\beta_{1}(\overbrace{y(t, t+2)-y(t, t+1)}^{\text {current slope }})+\epsilon
$$

where $\epsilon$ is a random shock. A change in the risk premium can move $y(t, t+2)$ without moving either $y(t, t+1)$ or $y(t+1, t+2)$. If this effect is dominant, the regression coefficient will be negative; i.e., $\beta_{1}<0$.
} 
to a persistently incorrect belief that the interest rate will begin to fall about twenty years from now or (2) to a decrease in the risk premium for bonds with maturities beyond twenty years, even though the uncertainty of the holding-period return for 30 -year bonds is greater that for 20-year bonds. Neither of these reasons is sensible. ${ }^{10}$

There is a sensible explanation (although it may seem counterintuitive at first) for the persistent downward slope of the term structure at the long end. The explanation has to do with the uncertainty regarding the future path of short-term rates. It is this uncertainty that underlies the risk of holding bonds. (If there were no uncertainty regarding the future path, there would be no risk to holding default-free bonds.) Increases in this uncertainty lead (1) to increases in risk premia that increase the slope of the yield curve at the short end and (2) to decreases in the slope of the yield curve at the long end via the effect of "convexity." Convexity (technically known as Jensen's Inequality) arises from the nonlinear relation between bond yields and bond prices. As a consequence, a symmetric increase in uncertainty about yields raises the average price of bonds, thereby lowering their current yields. This effect is trivial at the short end of the yield curve where it plays no significant role, but it becomes noticeable and even dominant at the long end. The overall shape of the yield curve involves the tradeoff between the competing effects of (1) risk premia (which cause longer-term yields to be higher) and (2) convexity (which cause longer term yields to be lower). Typically, the maximum yield occurs in 15to 25-year maturity range of the zero-coupon yield curve. ${ }^{11}$

It should be emphasized that expectations do in fact play an important role in determining changes in the shape of the yield curve. The reason the expectations hypothesis fails is not that expectations do not matter; rather it fails because it says that nothing else matters. But as we have seen, the expected future path of interest rates is but one of a number of important forces that shape the yield curve. When we try to explain the shape of a particular yield curve, we should ask what combination of expectations, risk premia, and convexity is consistent with this shape?

No-arbitrage conditions: An introduction. The problem we now face is that we have shown that the expectations hypothesis is not a good tool for studying the shape of the yield curve. The fundamental problem with the expectations hypothesis is that it is taken from a world of perfect certainty - where it is a condition for the absence of arbitrage opportunities - and transplanted into a world where there is uncertainty - where it is not. Fortunately, in recent years the theory of finance has produced better tools that allow us to directly apply the conditions that guarantee the absence of arbitrage opportunities in a world where there is uncertainty. The tools were developed as an outgrowth of the famous Black-Scholes model of option

\footnotetext{
${ }^{10}$ There is another explanation - not related to the expectations hypothesis - that is sensible. The downward slope at the long end of the yield curve could, in principle, reflect a substantial demand for the longest-maturity (default-free) zero-coupon bond (for example, to insulate the value of insurance companies long-term liabilities from interest-rate risk). Although the explanation is not unreasonable, it is unnecessary given the convexity effect discussed below.

${ }^{11}$ It should be stressed that the yield curve that is typically reported in the newspaper is not the zero-coupon yield curve and may display a somewhat different shape owing to a variety of factors.
} 
prices. The revolution in asset pricing that was initiated by the Black-Scholes model ultimately carried over to bond pricing and the term structure. ${ }^{12}$

An arbitrage involves trading securities in such a way as to generate something for nothing. Therefore, the conditions that guarantee the absence of arbitrage opportunities have to do with bond prices rather that bond yields. Thus, we are presented with a bit of a paradox: In order to understand the term structure (bond yields), we must move away from the expectations hypothesis (which focuses on yields) and focus instead on bond prices.

The most powerful tool for understanding the term structure of interest rates is called "the absence of arbitrage." This is short-hand for "the conditions that guarantee the absence of arbitrage opportunities." An opportunity for arbitrage exists when there is an inconsistency in the prices of securities that allows a valuable payoff to be obtained at no cost. For example, if there are two ways to obtain a given payoff and if one way is cheaper than the other, then one can take advantage of this situation by buying the payoff the inexpensive way ("buy low") and selling it the expensive way ("sell high"). The difference is the profit from an arbitrage. ${ }^{13}$

Anyone who prefers more to less would like to take advantage of an arbitrage opportunity. Smart and greedy investors are constantly on the lookout for arbitrage opportunities. In an active and liquid market such as the market for U.S. Treasury securities, any opportunities for arbitrage that might appear would be taken advantage of almost immediately. What happens to an arbitrage opportunity when someone tries to take advantage of it? Buying the payoff the inexpensive way puts upward pressure on the cost of obtaining the payoff this way, while selling the payoff the expensive way puts downward pressure on the cost of obtaining the payoff this way. The result is that opportunity for arbitrage tends to go away when someone tries to take advantage of it.

In order to understand the conditions that guarantee the absence of arbitrage opportunities, it is useful to think of financial securities as claims to state-dependent payoffs. Different securities contain differing amounts of each possible payoff. Insurance policies are particularly simple in this regard, because an insurance policy pays only when a specific state of the world occurs (for example, flood insurance pays only if there is a flood). Other securities may contain a wide variety of payoffs. Derivative securities, such as options, allow for the "disbundling" of the payoffs. For example, one can write a put option on a stock to insure against the fall in its price.

In principle, each of the payoffs in a security's bundle has a separate price. From this perspective, the price of the security is the sum of the (implicit) prices of the payoffs. Here is the key: As long as all of the individual payoffs have positive prices, there will be no opportunities for arbitrage. In other words, arbitrage opportunities

\footnotetext{
${ }^{12}$ See Black and Scholes (1973). In the Black-Scholes model, the stock price summarizes the "state of the world" for option prices. In the modeling the term structure, it is the interest rate (which is not the price of an asset) that summarizes the state of the world for bond prices. It is this difference that accounts for the time lag in adapting the Black-Scholes paradigm to bond prices.

${ }^{13}$ This example highlights the fact that when the "law of one price" is violated, an arbitrage opportunity exists.
} 
arise if one or more of the payoffs has a zero or negative price. The simplest example of an arbitrage is free insurance. (Free insurance generates something for nothing, but only in some states of the world.) More generally, a trading strategy that generates something for nothing involves buying and selling securities in such a way as to isolate and extract the mispriced payoffs.

These ideas can be illustrated concretely in a mundane setting. Consider a smart shopper at the grocery store. To keeps things simple, suppose the store sells only apples and oranges. Ordinarily when one goes to a store, one sees the posted prices for the produce. If one were to buy a bag containing, for example, two apples and three oranges, the price for the bag of produce would be computed from the prices posted for apples and oranges.

But this store is different. First of all, apples and oranges are sold mixed together in color-coded grocery bags. There are two combinations available: Red bags each contain two apples and three oranges, while blue bags each contain three apples and two oranges. The store posts prices for the bags, but not for apples or oranges separately. Even so, a smart shopper can figure out the implicit prices of apples and oranges from the prices of the bags. As long as the implicit prices of apples and oranges are both positive, there will be no arbitrage opportunities. But if the implicit price of either fruit is zero or negative, then one can get something for nothing.

There is another important difference between this store and an ordinary grocery store. Here one can not only buy bags of produce, one can sell them too. For example, if one has two apples and three oranges, one can put them in a red bag (which the store conveniently supplies for free), sell it to the store, and receive the posted price. This repackaging allows a smart shopper who only wants apples to buy only apples. For example, the shopper could buy three red bags (containing a total of nine apples and six oranges), sell two blue bags (containing a total of four apples and six oranges), and end up with five apples left over. The net cost of the apples is the difference between the revenue from selling the two blue bags less the expense of buying the three red bags. Suppose the price of red bags is $\$ 2$ and the price of blue bags is $\$ 3$. Then the net cost of apples is zero, and our smart shopper's "trading strategy" involving red and blue bags is an arbitrage: The smart shopper gets something for nothing. ${ }^{14}$

Faced with this arbitrage opportunity, why would the smart shopper limit the size of trading strategy? Why not buy 3,000 red bags and sell 2,000 blue bags, netting 5,000 apples? Or why not buy 3 million red bags and sell 2 million blue bags, netting 5 million apples? Or why not buy 3 billion ...? The reason, of course, is that at some point the purchases and sales will affect the prices of the bags, driving up the price of a red bag and driving down the price of a blue bag. The changing bag prices will indirectly affect the prices of the apples and oranges, raising the cost of apples. This reflects the general proposition that attempting to take advantage of arbitrage opportunities tends to make them disappear.

\footnotetext{
${ }^{14}$ In order to avoid arbitrage opportunities, the ratio of the cost of blue bags to red bags must be greater than two-thirds and less than three-halves. In this example, the ratio was exactly three-halves, which is allows arbitrage opportunities.
} 
How useful are no-arbitrage conditions? For some securities, the absence of arbitrage may not be very useful. Consider the prices of Microsoft stock and Bank of America stock. The absence of arbitrage does not tell us much about the relation between these two stock prices, because the state-contingent payoffs that the stocks "contain" do not overlap very much. For a different example, consider the price of Microsoft stock and an option to buy Microsoft stock. In this case, the payoffs are so closely related that the price of the option is completely determined by the no-arbitrage condition (i.e., the Black-Scholes model).

The term structure of interest rates is more like the second example than the first. In the stock/option example, there are two risky securities, but there is only one source of risk. Similarly for the term structure, there are more bonds than there are sources of risk. Because the payoffs to bonds of different maturities are highly correlated, the absence of arbitrage opportunities is quite useful. On the other hand, as noted above, there is an important difference between the term structure and the stock/option example. In that example, the state of the world is determined by the value of the stock. Because the stock is an asset, the formula for the value of an option is especially simple. In particular, investors attitudes toward risk play no role. However, for the term structure, the state of the world is determined by the interest rate, and the interest rate is not the value of an asset. Consequently, investors attitudes toward risk do play a role in the term structure.

\section{BOND PRICES AND ONE-PERIOD RETURNS}

The discount function. The simplest bond is a zero-coupon bond. It makes a single payment of one unit of payment at some fixed time in the future. For our purposes, we will let the unit of payment be the dollar, but the analysis will apply even if the payment were one peso or one "widget." Let $p(t, n)$ be the value at time $t$ of a zero-coupon bond that matures at time $t+n$, where $n$ is the term to maturity of the bond. ${ }^{15}$ Holding $t$ fixed and varying $n$ in $p(t, n)$ traces out the discount function at time $t$. The value of a zero-coupon bond tells us how much a risk-free payment paid in the future is worth today. We can immediately see two properties of bond prices. First, the value of one dollar to be delivered immediately is one dollar; i.e., $p(t, 0)=1$. (See Table 2.) Second, the value of a dollar to be delivered in the infinite future is zero; i.e., $\lim _{n \rightarrow \infty} p(t, n)=0 .{ }^{16}$ Figure 1 shows a discount function.

One-period returns. Suppose you buy an $n$-period bond today and sell it next period when it becomes an $(n-1)$-period bond. The net cash flows from this trading strategy are shown in Table 3 . The bond that costs $p(t, n)$ today can be sold for

\footnotetext{
$15_{\text {See Table }} 1$.

${ }^{16}$ This property holds if the interest rate is always positive. If the interest rate can be negative, then the discount function does not have to go to zero. So-called nominal interest rates cannot take on negative values because one can always hold currency instead (which has a nominal return of zero).
} 
TABLE 1. Notation

\begin{tabular}{ll}
\hline \hline$p(t, n)$ & $\begin{array}{l}\text { value at time } t \text { of an } n \text {-period bond (a bond that matures at } \\
\text { time } t+n)\end{array}$ \\
$r(t) \quad$ one-period interest rate at time $t(r(t)=1 / p(t, 1)-1)$
\end{tabular}

TABLE 2. The net cash flows associated with buying an $n$-period bond and holding it until maturity.

$\frac{\text { Net cash flows }}{\frac{\text { Today }(\text { time } t)}{-p(t, n)}} \frac{\text { At maturity }(\text { time } t+n)}{1}$

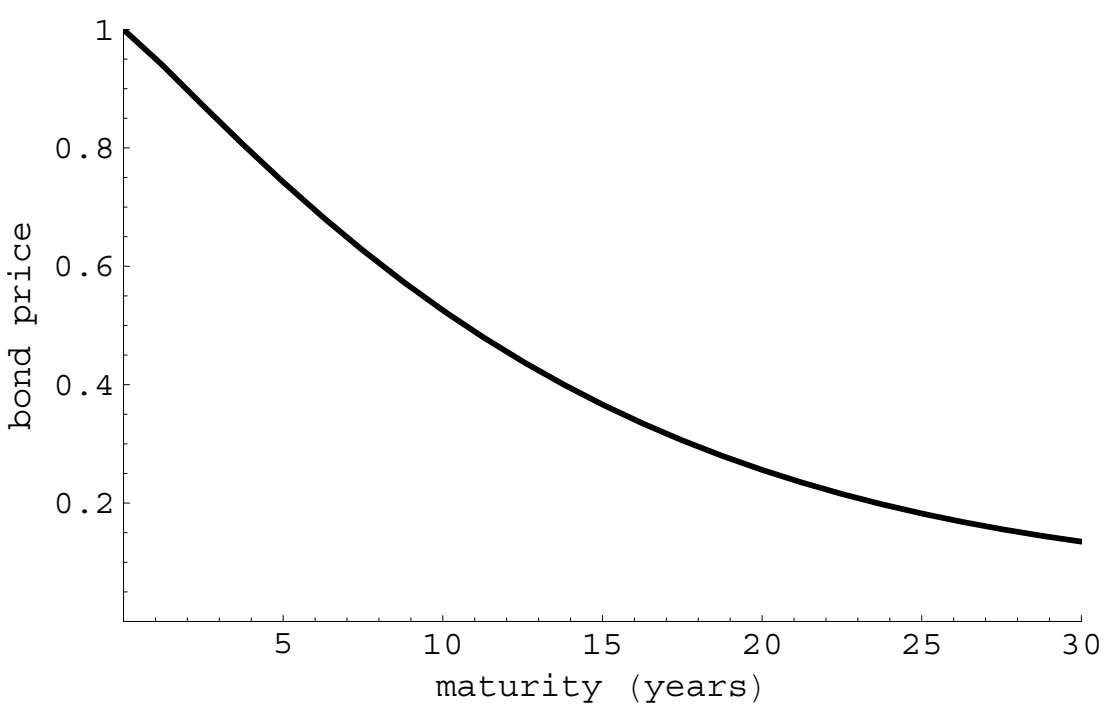

Figure 1. The discount function: The price of zero-coupon bonds.

$p(t+1, n-1)$ next period. The holding-period return for this investment is

$$
\frac{p(t+1, n-1)}{p(t, n)}-1=\frac{p(t+1, n-1)-p(t, n)}{p(t, n)},
$$

which is the amount one has at the end of the period divided by the amount one invested at the beginning of the period minus one.

In general, we do not know in advance what the price of an $(n-1)$-period bond will be next period, and consequently the holding period return is uncertain. The central point of this paper is to uncover the relation between the average holding period return and this uncertainty. 
TABLE 3 . The net cash flows associated with buying an $n$-period bond and holding it one period.

\begin{tabular}{c}
\hline$\frac{\text { Net cash flows }}{\text { Today (time } t)}$ \\
\hline$-p(t, n)$
\end{tabular}

For now, let us focus on the holding-period return on a one-period bond, which is known in advance since the one-period bond delivers one dollar without fail next period. (The net cash flows associated with buying a one-period bond are shown in Table 4.) We can define the one-period risk-free interest rate as this return. One can buy a one-period bond today for $p(t, 1)$. The amount repaid next period equals the amount lent plus interest:

$$
1=(1+r(t)) p(t, 1) .
$$

We can solve (2.1) for the one-period risk-free interest rate:

$$
r(t)=\frac{1}{p(t, 1)}-1
$$

TABLE 4. The net cash flows associated with buying a one-period bond.

\begin{tabular}{c}
\hline$\frac{\text { Net cash flows }}{\text { Today (time } t)}$ \\
$\frac{-p(t, 1)}{2}$
\end{tabular}

\section{TodAy'S PRICE: The PRESENT VAlue OF NEXT PERIOD'S PRICE}

Let us examine the relation between bond prices today and bond prices next period. We will do this by forming a portfolio today that costs nothing and seeing what it will be worth next period. We will buy an $n$-period bond and finance it by borrowing its cost at the one-period risk-free rate. (In other words, we sell oneperiod bonds of equal value.) The net cash flow at time $t$ is zero. Next period, we sell the long-term bond and pay off the debt (principal plus interest). Table 5 summarizes the net cash flows for this trading strategy.

If it is known today that $p(t+1, n-1)$ will be greater than $(1+r(t)) p(t, n)$, then our trading strategy is an arbitrage: We get something (next period) for nothing (today). On the other hand, if it is known today that $p(t+1, n-1)$ will be less than $(1+r(t)) p(t, n)$, we can modify our trading strategy to make it an arbitrage. Instead of buying the long-term bond and selling some one-period bonds, we can sell the long-term bond and buy the one-period bonds. The net cash flows for this trading strategy are the same as for our original trading strategy except that the signs are 
TABLE 5. Net cash flows associated with financing the purchase of an $n$-period bond with one-period borrowing.

\begin{tabular}{|c|c|}
\hline \multicolumn{2}{|r|}{ Net cash flows } \\
\hline Today (time $t$ ) & Next period (time $t+1)$ \\
\hline 0 & $p(t+1, n-1)-(1+r(t)) p(t, n)$ \\
\hline
\end{tabular}

reversed. The upshot is that in a world of no uncertainty, the absence-of-arbitrage condition for bond prices is

$$
p(t+1, n-1)-(1+r(t)) p(t, n)=0 .
$$

We can solve (3.1) for today's price of the long-term bond:

$$
p(t, n)=\frac{p(t+1, n-1)}{1+r(t)} .
$$

In other words, the price of the bond today is the present value of its price next period. Another way to express this is

$$
\frac{p(t+1, n-1)-p(t, n)}{p(t, n)}=r(t),
$$

which says that the (net) return on a bond equals the risk-free interest rate.

\section{UNCERTAINTY}

The bonds we will deal with in this paper are default-free - all promised payments are made in full and on time. Nevertheless, these bonds have risk prior to maturity: They can gain or lose value. This uncertainty regarding bond prices can (and will) be linked to the uncertainty regarding interest rates, and this latter uncertainty can be viewed as more fundamental. Nevertheless, the effect of that uncertainty on bond prices and on the conditions that guarantee the absence of arbitrage opportunities can be studied without reference to the underlying interest-rate uncertainty.

In the previous section, we established an absence-of-arbitrage condition based on knowing next period's bond value with certainty. (See Equation (3.1).) What if the bond's value next period is not known with certainty? What if its possible values can make the net cash flow for a trading strategy sometimes positive and sometimes negative? In this case, the trading strategy is not an arbitrage. The conditions for the absence of arbitrage opportunities are not sufficiently restrictive to completely establish the relation between today's price and next period's price when there is uncertainty. Nevertheless, they do put enough structure on bond prices to provide very useful results.

Heads or tails? All bond prices tend to go up and down together. When the short-term interest rate rises, all bond prices tend to fall, and conversely when the short-term interest rate falls, all bond prices tend to rise. To keep things simple, suppose there are only two possible discount functions next period. The flip of an 
TABLE 6. Notation: Bond-price uncertainty

\begin{tabular}{|c|c|}
\hline$p_{n}$ & value of an $n$-period bond (same as $p(t, n)$ ) \\
\hline$r$ & one-period interest rate (same as $r(t)$ ) \\
\hline$p_{n-1}^{H}$ & $\begin{array}{l}\text { value next period of an }(n-1) \text {-period bond if the coin comes } \\
\text { up heads }\end{array}$ \\
\hline$p_{n-1}^{T}$ & $\begin{array}{l}\text { value next period of an }(n-1) \text {-period bond if the coin comes } \\
\text { up tails }\end{array}$ \\
\hline $\bar{p}_{n-1}$ & average value of an $(n-1)$-period bond (pre-flip) \\
\hline$\delta_{n-1}^{p}$ & volatility of the bond price (amount of risk) \\
\hline$a_{n-1}$ & adjustment term (risk premium) \\
\hline
\end{tabular}

unbiased coin will determine which discount function is realized. ${ }^{17}$ In other words, if one were to buy an $n$-period bond today, there would be two possibilities for the price of an $(n-1)$-period bond next period, with the actual outcome determined by the flip of a coin. We can simplify the notation a bit if we limit ourselves to considering just today (time $t$ ) and tomorrow (time $t+1$ ). Let the price today of an $n$-period bond be $p_{n}$. If the coin comes up heads the price of bond tomorrow will be $p_{n-1}^{H}$ and if it comes up tails the price will be $p_{n-1}^{T}$. Let $\bar{p}_{n-1}$ denote the average price of the bond next period:

$$
\bar{p}_{n-1}=\frac{p_{n-1}^{H}+p_{n-1}^{T}}{2} .
$$

Let $\delta_{n-1}^{p}$ denote the volatility of the bond price next period:

$$
\delta_{n-1}^{p}=\frac{p_{n-1}^{H}-p_{n-1}^{T}}{2} .
$$

Volatility is a measure of the riskiness of the investment. It is related to the variance and the standard deviation. ${ }^{18}$ Volatility is more useful than standard deviation because volatility's sign plays a role in characterizing whether the risk is bad or good. (An insurance policy is an example of an investment that has good risk, because it pays off in bad times). Table 7 shows the value of the $(n-1)$-period bond next period as determined the coin flip. Figure 2 plots two post-flip discount functions and their average.

\footnotetext{
${ }^{17}$ An unbiased coin has a 50-50 chance of coming up either heads or tails.

${ }^{18}$ The variance is the average squared deviation from the mean,$$
\frac{1}{2}\left(p_{n-1}^{H}-\bar{p}_{n-1}\right)^{2}+\frac{1}{2}\left(p_{n-1}^{T}-\bar{p}_{n-1}\right)^{2}=\left(\delta_{n-1}^{p}\right)^{2},
$$

and the standard deviation is the square root of the variance, which is the absolute value of the volatility, $\left|\delta_{n-1}^{p}\right|$. 
TABLE 7 . The value of an $n$-period next period (when it becomes an $(n-1)$-period bond) after the coin flip. The average price is $\bar{p}_{n-1}$ and the volatility of the price is $\delta_{n-1}^{p}$.

\begin{tabular}{|c|c|}
\hline Heads & Tails \\
\hline$p_{n-1}^{H}=\bar{p}_{n-1}+\delta_{n-1}^{p}$ & $p_{n-1}^{T}=\bar{p}_{n-1}-\delta_{n-1}^{p}$ \\
\hline
\end{tabular}

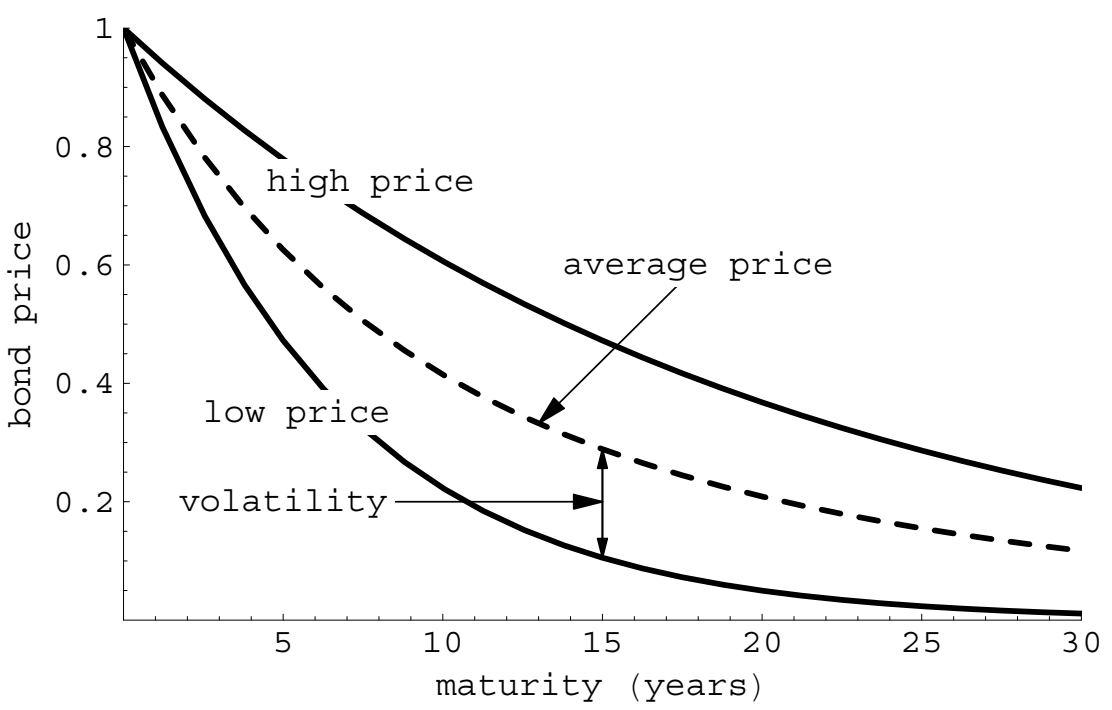

Figure 2. Two post-flip discount functions and the average of the two. The volatility is a measure of the uncertainty.

Although there is no need to specify which of the two post-flip prices is greater, for the sake of concreteness we will assume (in Section 4) that $p_{n-1}^{H}>p_{n-1}^{T}$ and therefore $\delta_{n-1}^{p}>0$.

The absence of arbitrage opportunities under uncertainty: Part I. Recall that an arbitrage is a trading strategy that generates something for nothing. Now that uncertainty has been introduced, we need to reexamine what the absence of arbitrage implies. Suppose there were a trading strategy that had zero net cash flow today. In other words, the trading strategy costs nothing. The conditions for absence of arbitrage opportunities can be stated in terms of the net cash flows next period as follows: Either $(i)$ they are both zero (as they must be in the case of no uncertainty) or (ii) one is positive and the other is negative.

To see why this must be so, suppose the contrary were true. If, for example, they were both positive, then the trading strategy would clearly generate an arbitrage: One would get something - in all states of the world next period - for nothing today. On the other hand, suppose only one net cash flow were positive next period and the other were zero. This too would be an arbitrage: Just like free insurance, it would 
cost nothing today and make positive payoffs in some states of the world next period, without the possibility of negative payoffs. Alternativley, if both payoffs were negative (or one negative and the other zero), one could reverse the signs of the payoffs by reversing the positions in the trading strategy (for example, selling instead of buying, lending instead of borrowing).

We can apply this analysis to the following simple trading strategy: Buy an $n$-period bond today and finance its purchase price with one-period risk-free borrowing. The net cash flow today is zero, and the possible net cash flows next period are $p_{n-1}^{H}-(1+r) p_{n}$ and $p_{n-1}^{T}-(1+r) p_{n}$, as shown in Table 8 . If there were no uncertainty $\left(p_{n-1}^{T}=p_{n-1}^{H}\right)$, the no-arbitrage condition would be that both net cash flows next period must be zero. But when there is uncertainty $\left(p_{n-1}^{T} \neq p_{n-1}^{H}\right)$, the two net cash flows cannot both be zero. In this case, the no-arbitrage condition is that $(1+r) p_{n}$ must lie between $p_{n-1}^{H}$ and $p_{n-1}^{T}$, thereby guaranteeing that one net cash flow is positive and the other negative. ${ }^{19}$

TABLE 8. Net cash flows at $t+1$ associated with financing the purchase of an $n$-period bond with one-period borrowing.

\begin{tabular}{|c|c|c|}
\hline \multicolumn{3}{|c|}{ Net cash flows } \\
\hline Time $t$ & \multicolumn{2}{|c|}{ Time $t+1$} \\
\hline & Heads & Tails \\
\hline 0 & $p_{n-1}^{H}-(1+r) p_{n}$ & $p_{n-1}^{T}-(1+r) p_{n}$ \\
\hline
\end{tabular}

Today's price: The present value of next period's adjusted average price. We can get some guidance in how to proceed by aping the relation between today's price and next period's price that we established when there was no uncertainty. The simplest and most natural way to modify (3.2) so that it makes sense when the value of a bond next period is not certain is to replace the uncertain price next period with its average:

$$
p_{n}=\frac{\bar{p}_{n-1}}{1+r}
$$

where $r=r(t)$. Equation (4.2) says that today's bond price is the present value of the "expected value" of tomorrow's bond price. ${ }^{20}$ Equation (4.2) can be written as

$$
\frac{\bar{p}_{n-1}-p_{n}}{p_{n}}=r
$$

which says that the expected return on a long-term bond equals the risk-free rate (i.e., the risk-free return on a one-period bond).

\footnotetext{
${ }^{19}$ This condition guarantees that the realized return on the $n$-period bond is greater than $r$ if the coin comes up heads and less that $r$ if it comes up tails.

${ }^{20}$ Equation (4.2) is an expectations hypothesis, albeit one based on bond prices rather than on interest rates. In Section 8 we will discuss the typical statement of the expectations hypothesis, namely that forward rates are expectations of future one-period returns.
} 
But why should investors be willing to earn exactly the risk-free rate on average? If the uncertainty associated with owning bonds contributes to the overall uncertainty of investors' lives, investors may require a higher average return to take on this additional risk. On the other hand, if the uncertainty associated with owning bonds reduces the overall uncertainty of their lives, they may accept an average return that is less than the risk-free rate.

In order to account for how investors feel about the kind of risk they face, we can incorporate an adjustment term $\left(a_{n-1}\right)$ into the formula for today's bond price:

$$
p_{n}=\frac{\bar{p}_{n-1}-a_{n-1}}{1+r} \text {. }
$$

We refer to $\bar{p}_{n-1}-a_{n-1}$ as the adjusted average price. Equation (4.4) says that today's price is the present value of next period's adjusted average price. We can rearrange (4.4) to express the expected return for the bond:

$$
\frac{\bar{p}_{n-1}-p_{n}}{p_{n}}=r+\frac{a_{n-1}}{p_{n}} \text {. }
$$

Equation (4.5) says that the average holding-period return for a bond is the risk-free rate plus an additional term that somehow accounts for the amount and type of risk involved.

The adjustment term, which can be positive, negative, or zero, provides great flexibility within certain bounds. We have already shown that $(1+r) p_{n}$ must be between $p_{n-1}^{H}$ and $p_{n-1}^{T}$ in order to avoid arbitrage opportunities. Given (4.4), these boundaries imply the adjusted average price, $\bar{p}_{n-1}-a_{n-1}$, must also be between $p_{n-1}^{H}$ and $p_{n-1}^{T}$ (since $(1+r) p_{n}$ equals the adjusted average price). Within these bounds, any bond price (or expected return) can be obtained with a suitable choice for the adjustment term. Putting this the other way around, we cannot rule out any bond prices in this range. In other words, thus far the theory of bond pricing under uncertainty provides very little structure. To obtain more structure, we need to examine how two different long-term bonds interact.

TABLE 9. Notation: Bond portfolios

\begin{tabular}{ll}
\hline \hline$b$ & number of $m$-period bonds held in portfolio \\
$b^{*}$ & number of $m$-period bonds held to make the portfolio risk-free \\
$\pi^{H}$ & value the portfolio next period if the coin comes up heads \\
$\pi^{T}$ & value the portfolio next period if the coin comes up tails \\
$\pi^{*}$ & value of risk-free portfolio (holding $b^{*} m$-period bonds) \\
$\lambda$ & price of risk \\
\hline \hline
\end{tabular}

The absence of arbitrage opportunities under uncertainty: Part II. In this section, we examine arbitrage opportunities that involve simultaneously buying and 
selling bonds with different maturities in order to form a risk-free portfolio. ${ }^{21}$ By doing so, we will uncover the condition that guarantees the absence of arbitrage opportunities, which, as we will see, has something important to say about how the adjustment terms on different bonds are related to each other.

Consider the following portfolio of two bonds: Buy one $n$-period bond and buy (or sell) some $m$-period bonds (where $m$ is different from $n$ ). Let $b$ denote the number of $m$-period bonds purchased (where $b$ is negative if they are sold). The cost of this portfolio today is

$$
p_{n}+b p_{m}
$$

which may be positive, negative, or zero. Let $\pi^{H}$ and $\pi^{T}$ represent the possible values of this portfolio next period. These values are shown Table 10 .

TABLE 10. The value of the portfolio after the coin flip.

\begin{tabular}{|c|c|}
\hline Heads & Tails \\
\hline$\pi^{H}=p_{n-1}^{H}+b p_{m-1}^{H}$ & $\pi^{T}=p_{n-1}^{T}+b p_{m-1}^{T}$ \\
\hline
\end{tabular}

Each of these two bonds is risky in isolation. But since the uncertainty for each of these bonds is driven by the same underlying source of risk, it is possible to combine the bonds in such a way as to reduce the overall risk. In fact, there is a value for $b$ $\left(\right.$ call it $b^{*}$ ) that makes the portfolio completely risk free. In other words, the value of the portfolio next period the same in both states of the world, so that $\pi^{H}=\pi^{T}$. For this to be true, $b^{*}$ must satisfy

$$
p_{n-1}^{H}+b^{*} p_{m-1}^{H}=p_{n-1}^{T}+b^{*} p_{m-1}^{T} .
$$

We can solve Equation (4.6) for

$$
b^{*}=-\left(\frac{p_{n-1}^{H}-p_{n-1}^{T}}{p_{m-1}^{H}-p_{m-1}^{T}}\right)=-\left(\frac{\delta_{n-1}^{p}}{\delta_{m-1}^{p}}\right) .
$$

Since $b^{*}$ is negative, this portfolio involves selling some $m$-period bonds. In other words, $b^{*}$ is a hedge ratio - it tells us how to use one bond to hedge the risk of another so that on balance there is no risk at all. ${ }^{22}$ Let $\pi^{*}$ denote the known payoff to this risk-free portfolio. Since $\pi^{*}$ can be computed from either side of Equation (4.6), it must equal to the average of the two sides:

$$
\pi^{*}=\bar{p}_{n-1}+b^{*} \bar{p}_{m-1} .
$$

Consider the following trading strategy. Form the risk-free portfolio of bonds and finance it with one-period borrowing. The net cash flows associated with this trading strategy are shown in Table 11. Since the net cash flow today is zero and the net cash flow next period is certain, there will be an arbitrage opportunity

\footnotetext{
${ }^{21}$ See Vasicek (1977) for an early application of the absence of arbitrage to the term structure of interest rates.

${ }^{22}$ This is analogous to delta hedging in option pricing.
} 
TABLE 11. Net cash flows associated with financing the purchase of the risk-free portfolio with one-period borrowing.

\begin{tabular}{|c|c|}
\hline \multicolumn{2}{|c|}{ Net cash flows } \\
\hline Today (time $t$ ) & Next period (time $t+1)$ \\
\hline 0 & $\pi^{*}-(1+r)\left(p_{n}+b^{*} p_{m}\right)$ \\
\hline
\end{tabular}

unless the cash flow next period is zero. Therefore, the condition for the absence of arbitrage opportunities is

$$
\pi^{*}-(1+r)\left(p_{n}+b^{*} p_{m}\right)=0 .
$$

In order to see what this condition implies for the adjustment terms of the two bonds, we can use Equation (4.4) to reexpress the cost of this portfolio using the adjusted average prices:

$$
\begin{aligned}
p_{n}+b^{*} p_{m} & =\overbrace{\left(\frac{\bar{p}_{n-1}-a_{n-1}}{1+r}\right)}^{p_{n}}+b^{*} \overbrace{\left(\frac{\bar{p}_{m-1}-a_{m-1}}{1+r}\right)}^{p_{m}} \\
& =\frac{(\overbrace{\bar{p}_{n-1}+b^{*} \bar{p}_{m-1}}^{\pi^{*}})}{1+r}-\frac{\left(a_{n-1}+b^{*} a_{m-1}\right)}{1+r} \\
& =\frac{\pi^{*}}{1+r}-\frac{\left(a_{n-1}+b^{*} a_{m-1}\right)}{1+r} .
\end{aligned}
$$

Now we can replace $p_{n}+b^{*} p_{m}$ in the no-arbitrage condition (4.8) with the last line on the right-hand side of Equation (4.9), so that the no-arbitrage condition becomes

$$
a_{n-1}+b^{*} a_{m-1}=0 \text {. }
$$

Equation (4.10) shows that the adjustment terms play a central role in the condition that guarantees the absence of arbitrage opportunities.

We are now ready to find the final expression for the absence-of-arbitrage condition. Substituting the solution for $b^{*}$ given in Equation (4.7) into Equation (4.10) and rearranging produces

$$
\frac{a_{n-1}}{\delta_{n-1}^{p}}=\frac{a_{m-1}}{\delta_{m-1}^{p}}
$$

Equation (4.11) says that the ratio of the adjustment term to the bond-price volatility must be the same for both bonds. This common ratio is called the price of risk. Let $\lambda$ denote the price of risk, so that

$$
\lambda=\frac{a_{n-1}}{\delta_{n-1}^{p}}=\frac{a_{m-1}}{\delta_{m-1}^{p}} .
$$

The absence-of-arbitrage condition does not say whether the price of risk is big or small or even whether it is positive, negative, or zero; it only says that it must be the same for all bonds. 
The adjustment term is the risk premium. Given the absence-of-arbitrage condition we have just established, we can write the adjustment term as

$$
a_{n-1}=\lambda \delta_{n-1}^{p},
$$

where $\lambda$ is the price of risk and $\delta_{n-1}^{p}$ is the volatility of the bond's price. We can express Equation (4.12) as

$$
\text { risk premium }=\text { price of risk } \times \text { amount of risk. }
$$

In other words, the adjustment term is the risk premium and the volatility of the bond price is the amount of risk that earns a premium.

The condition for the absence of arbitrage opportunities can be stated in terms of the expected return on a bond by substituting (4.12) into (4.5):

$$
\frac{\bar{p}_{n-1}-p_{n}}{p_{n}}=r+\lambda\left(\frac{\delta_{n-1}^{p}}{p_{n}}\right)
$$

where $\delta_{n-1}^{p} / p_{n}$ is the relative volatility of the bond price; it measures the volatility of the holding-period return. We can express Equation (4.13) as

$$
\text { expected return }=\text { risk-free rate }+(\text { relative }) \text { risk premium, }
$$

where the relative risk premium equals the price of risk times the amount of risk as measured by the relative volatility of the bond price. In other words, the extra return one gets (from the risk premium) depends on the amount of risk $\left(\delta_{n-1}^{p} / p_{n}\right)$ and the price of risk $(\lambda)$. If either is zero, there is no risk premium. ${ }^{23}$

\section{BOND YIELDS AND CONVEXITY}

In this section, we define the yield to maturity and show how to express the absence-of-arbitrage conditions in terms of yields.

TABLE 12. Notation: Bond yields and compounding

\begin{tabular}{ll}
\hline \hline$y^{i}(t, n)$ & $\begin{array}{l}\text { yield at time } t \text { on an } n \text {-period bond, compounded } i \text { times per } \\
\text { period) }\end{array}$ \\
$y^{1}(t, n)$ & yield computed with simple compounding \\
$y^{1}(t, 1)$ & same as $r(t)$ \\
$y(t, n)$ & continuously-compounded yield (same as $\left.y^{\infty}(t, n)\right)$ \\
\hline \hline
\end{tabular}

\footnotetext{
${ }^{23}$ In Appendix A we show that the risk premium can be interpreted as a covariance with a market-wide factor. As a consequence, (4.13) has the same form as the Capital Asset Pricing Model (CAPM), in which the expected return on an equity equals the risk-free rate plus a riskpremium that depends on the covariance with the market portfolio.
} 
Yield to maturity. Suppose you buy an $n$-period bond. If you were to hold it until it matured, what would the return on your investment be? The amount invested is $p(t, n)$ and the amount returned is one, so the total gross return is simply

$$
\frac{1}{p(t, n)} \text {. }
$$

From the total gross return, we can compute the gross return per period:

$$
p(t, n)^{-1 / n}=\frac{1}{\sqrt[n]{p(t, n)}},
$$

since

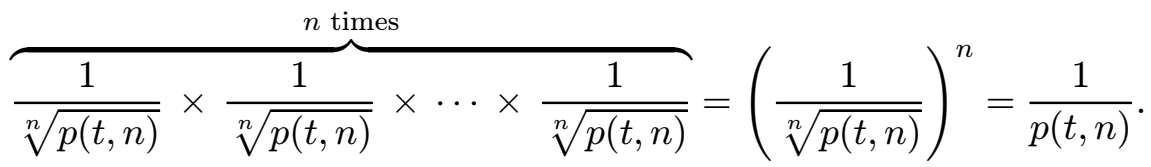

Typically, however, it is not the gross return period that is used to characterize the return, but the rather the net return per period. The net per-period return is called the yield to maturity (or simply the yield). The yield is like an "interest rate." There is a degree of freedom in computing interest rates: How many times per period is interest assumed to be compounded? The fact that there are only two points in time under consideration (the beginning of the period and the end of the period) does not resolve the issue, since one is free to quote the interest rate as if there were subperiods over which compounding takes place. Let $y^{i}(t, n)$ denote the value of $y$ that solves the following equation for a given $i$ :

$$
\left(1+\frac{y}{i}\right)^{i}=p(t, n)^{-1 / n} \quad i=1,2,3, \ldots
$$

The solution is

$$
y^{i}(t, n)=i\left(p(t, n)^{-1 /(n i)}-1\right) .
$$

Given the price of the bond, each and every $y^{i}(t, n)$ has a right to be called the net return per period. How one chooses to quote the return (i.e., the value one chooses for $i$ ) is merely a matter of convenience.

There are two rates of compounding that are particularly convenient to use, and they happen to lie at opposite ends of the compounding spectrum. The first case is called simple compounding, where interest is compounded only once per period $(i=1)$ :

$$
y^{1}(t, n)=\frac{1}{\sqrt[n]{p(t, n)}}-1
$$

We used simple compounding to compute the one-period risk-free rate above:

$$
r(t)=y^{1}(t, 1)
$$

The second case is called continuous compounding, where interest is compounded infinitely many times per period $(i=\infty)$. We will use $y(t, n)$ (without the symbol for 
infinity) to denote continuously-compounded yields. Fortunately there is a simple formula for continuously-compounded yields: ${ }^{24}$

$$
y(t, n)=\frac{-\log (p(t, n))}{n} .
$$

We use continuously-compounded yields when we talk about the yield curve. Figure 3 plots the yield curve computed from the discount function that is plotted in Figure 1.

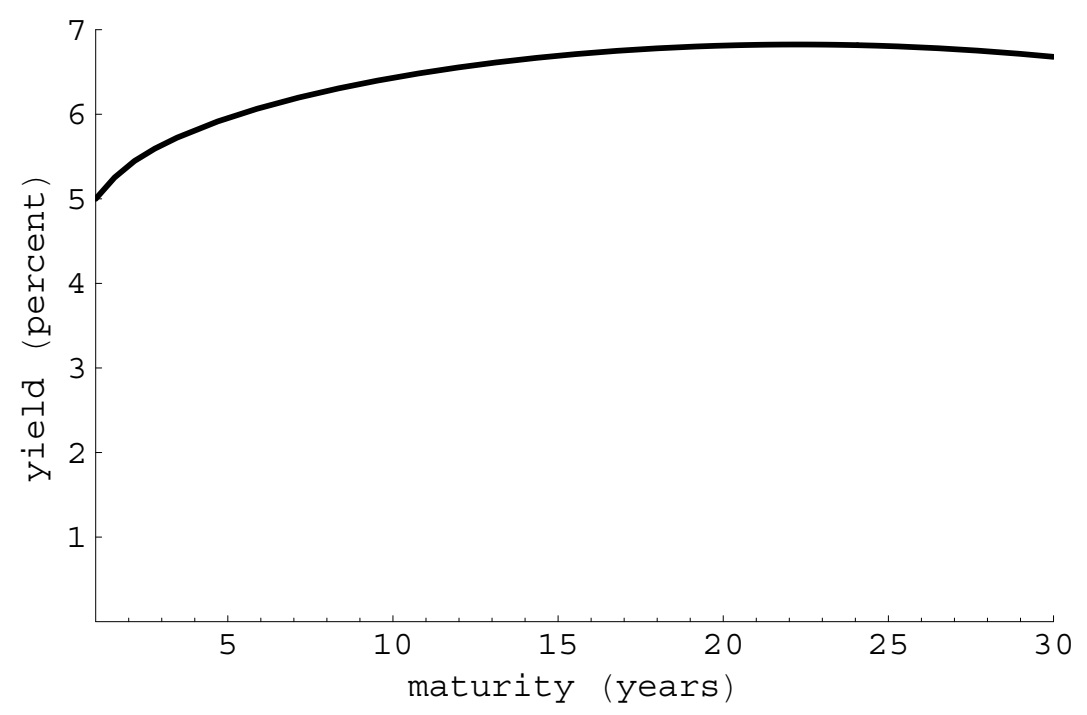

FigURE 3. The zero-coupon yield curve computed from the discount function shown in Figure 1.

A first look at the expectations hypothesis. The expectations hypothesis can be expressed in a number of equivalent ways. Here is one way to express it: The long-term yield equals the average of the (expected) one-period yields. Of course when there is no uncertainty, expected one-period yields equal the actual one period yields. In this case we can write the expectations hypothesis as

$$
y(t, n)=\frac{y(t, 1)+y(t+1,1)+\cdots+y(t+n-1,1)}{n} .
$$

But Equation (5.1) is not just a statement of the expectations hypothesis; when there is no uncertainty it is also a statement of the absence of arbitrage opportunities.

We can show this as follows. According to Equation (3.2), the value of an $n$ period bond today is the present value of next period's value of a $(n-1)$-period bond:

$$
p(t, n)=\frac{p(t+1, n-1)}{1+r(t)}=p(t, 1) p(t+1, n-1) .
$$

\footnotetext{
${ }^{24}$ Formally, the continuously-compounded yield is a limit: $y(t, n)=\lim _{i \rightarrow \infty} y^{i}(t, n)$.
} 
The second equality follows from $p(t, 1)=1 /(1+r(t))$. Now we can apply Equation (3.2) to the price of an $(n-1)$-period bond at time $t+1$ :

$$
p(t+1, n-1)=\frac{p(t+2, n-2)}{1+r(t+1)}=p(t+1,1) p(t+2, n-2) .
$$

Combining Equations (5.2) and (5.3), we have

$$
p(t, n)=p(t, 1) p(t+1,1) p(t+2, n-2) .
$$

We can continue this process until we end up with the price of a long-term bond expressed as the product of one-period bond prices:

$$
p(t, n)=p(t, 1) p(t+1,1) \cdots p(t+n-1,1) .
$$

Now if we take logs of both sides of Equation $(5.4)^{25}$ and divide by $-n$ we get Equation (5.1).

Since the expectations hypothesis is equivalent to the absence-of-arbitrage conditions when there is no uncertainty, it is understandable that some people may have thought that the same equivalence is true where there is uncertainty-understandable, but wrong.

Uncertainty and convexity. At this point, we examine the effect of uncertainty on bond yields. We will see how uncertainty per se drives a wedge between the expected future yields and current yields.

The relation between bond prices and bond yields is not linear; consequently, the yield computed from the average bond price is less than the average yield. ${ }^{26}$ In this section we demonstrate this point and explore its consequences.

TABLE 13. Notation: Bond yield uncertainty (continuously compounded)

\begin{tabular}{ll}
\hline \hline$y_{n}$ & yield at time $t$ on an $n$-period bond (same as $y(t, n))$ \\
$y_{n-1}^{H}$ & yield next period on an $(n-1)$-period bond if the coin comes \\
& up heads \\
$y_{n-1}^{T}$ & yield next period on an $(n-1)$-period bond if the coin comes \\
& up tails \\
$\bar{y}_{n-1}$ & average yield on an $(n-1)$-period bond (pre-flip) \\
$\delta_{n-1}^{y}$ & volatility of the yield \\
\hline \hline
\end{tabular}

The relation between bond yields and bond prices, $y_{n}=-\log \left(p_{n}\right) / n$, is plotted in Figure 4 for ten- and twenty-year bonds. The two primary features that are evident in the figure are (1) the negative slope and (2) the fact that the graph of the function is "bowed in" toward the origin -in other words, convex to the origin. ${ }^{27}$

\footnotetext{
${ }^{25}$ Recall that $\log (a b)=\log (a)+\log (b)$.

${ }^{26}$ This is an example of what is technically known as Jensen's inequality.

${ }^{27}$ These two features summarize the first two derivatives of the bond yield with respect to the price. The first derivative is negative and the second derivative is positive.
} 


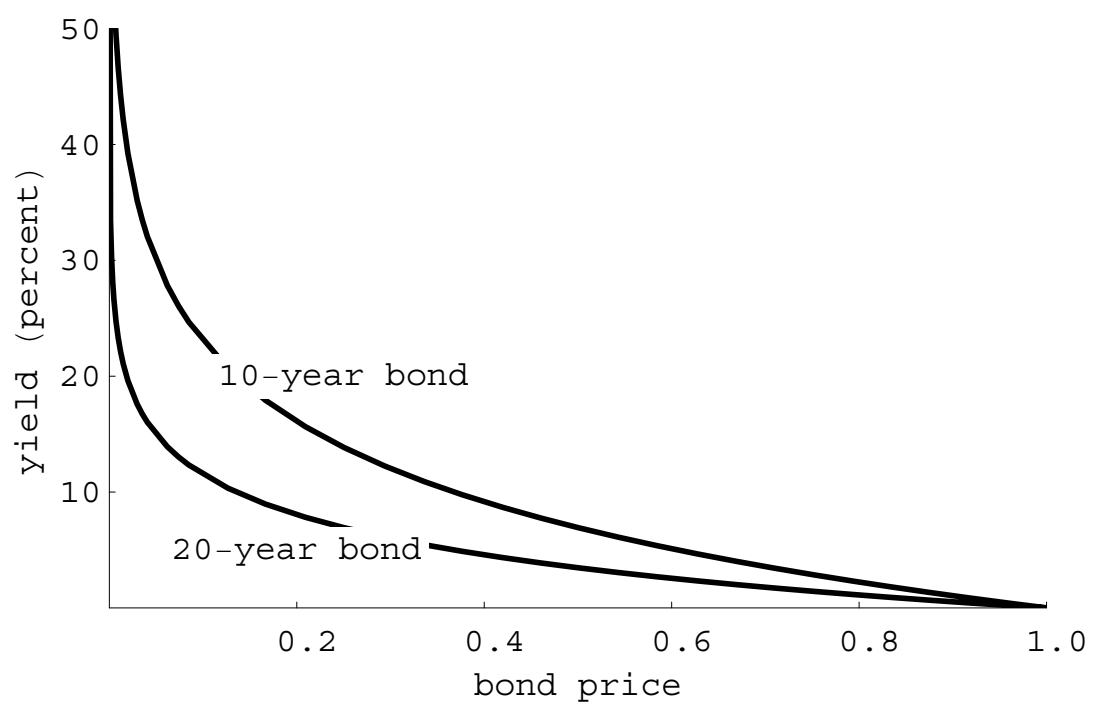

FiguRE 4. The yield of zero-coupon bonds as a function of the price.

This second feature is called convexity. Figure 4 shows that a twenty-year bond has more convexity than a ten-year bond.

Convexity drives a wedge between the average yield and the yield of the average price. This is illustrated in Figure 5. There are two outcomes that depend on the flip of the coin: (1) high price and low yield or (2) low price and high yield. The average price and the average yield are at the midpoint of the straight line that connects the two outcomes. But the yield computed from the average price lies on the heavy curved line, below the average yield.

Let us derive an algebraic expression for the effect of convexity. Using continuous compounding, we can compute the post-flip yields from the two post-flip bond prices:

$$
y_{n-1}^{H}=\frac{-\log \left(p_{n-1}^{H}\right)}{n-1} \quad \text { and } \quad y_{n-1}^{T}=\frac{-\log \left(p_{n-1}^{T}\right)}{n-1} .
$$

We can express the post-flip yields as

$$
y_{n-1}^{H}=\bar{y}_{n-1}+\delta_{n-1}^{y} \quad \text { and } \quad y_{n-1}^{T}=\bar{y}_{n-1}-\delta_{n-1}^{y},
$$

where the average yield and the volatility of the yield are given by

$$
\bar{y}_{n-1}=\frac{y_{n-1}^{H}+y_{n-1}^{T}}{2} \quad \text { and } \quad \delta_{n-1}^{y}=\frac{y_{n-1}^{H}-y_{n-1}^{T}}{2} .
$$

As an example, suppose the current one-period yield equals the average longterm yield, $y_{1}=\bar{y}_{n-1}=\bar{y}$, for all $n \geq 2$, and also suppose the yield volatility is constant, $\delta_{n-1}^{y}=\delta^{y}$. Then the yield on an $n$-period bond (i.e., the yield curve) can be approximated by

$$
y_{n} \approx \bar{y}-n \frac{1}{2}\left(\delta^{y}\right)^{2}
$$




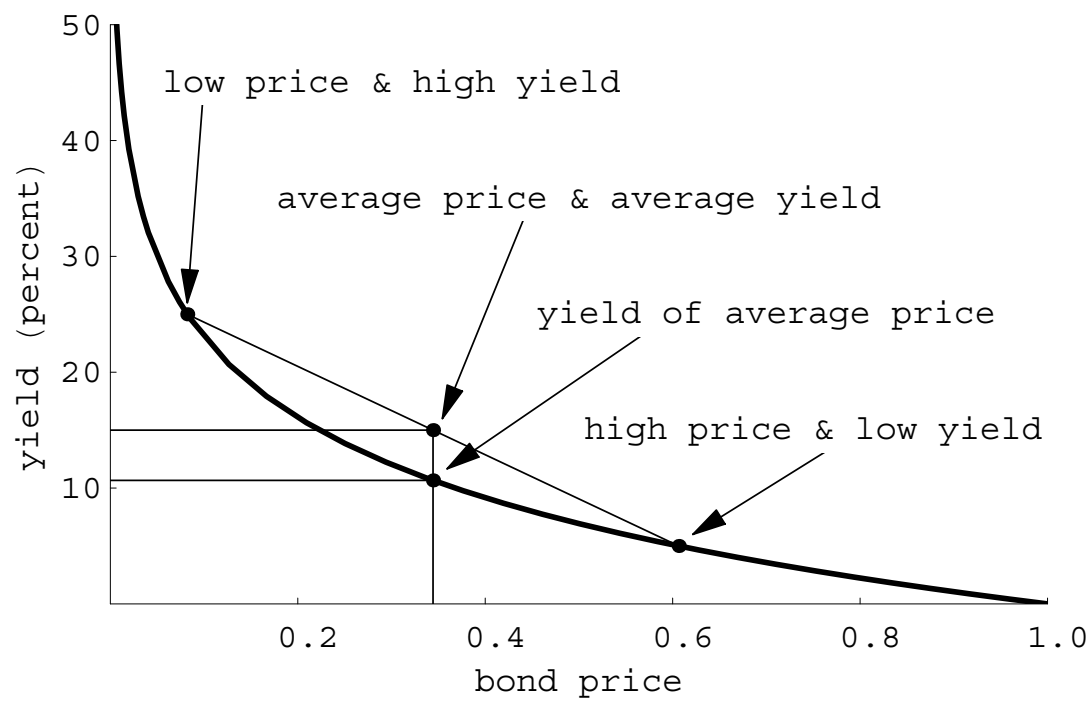

FiguRE 5. Convexity drives a wedge between the average yield and the yield of the average price.

as long as $n$ is not too big. This approximation illustrates the three main features of convexity.

(1) Convexity has the effect of reducing yields.

(2) The convexity effect is larger for longer-term bonds.

(3) The convexity effect depends on the variance of the uncertainty about yields. See Figure 6 for an example where $\bar{y}=0.10$ and $\delta^{y}=0.05 .^{28}$

This example illustrates the depressing effect of uncertainty on bond yields via the convexity effect. As noted in the introductory section, risk premia will also have an effect on the shape of the term structure. Part 2 provides a full treatment of the effect of the effect of risk premia.

\section{Part 2. Additional material; not duplicated by the Review article}

\section{BOND PRICES, BOND YIELDS, AND UNCERTAINTY}

We can express the average price of an $(n-1)$-period bond in terms of the yields:

$$
\begin{aligned}
\bar{p}_{n-1} & =\frac{1}{2}\left(p_{n-1}^{H}+p_{n-1}^{T}\right) \\
& =\frac{1}{2}\left(e^{-(n-1) y_{n-1}^{H}}+e^{-(n-1) y_{n-1}^{T}}\right) \\
& =e^{-(n-1) \bar{y}_{n-1}} \frac{1}{2}\left(e^{(n-1) \delta_{n-1}^{y}}+e^{-(n-1) \delta_{n-1}^{y}}\right) \\
& =e^{-(n-1) \bar{y}_{n-1}} \cosh \left((n-1) \delta_{n-1}^{y}\right),
\end{aligned}
$$

\footnotetext{
${ }^{28}$ The graph is drawn using the exact formula, upon which the approximation is based. See Part 2 of the companion working paper for the details.
} 


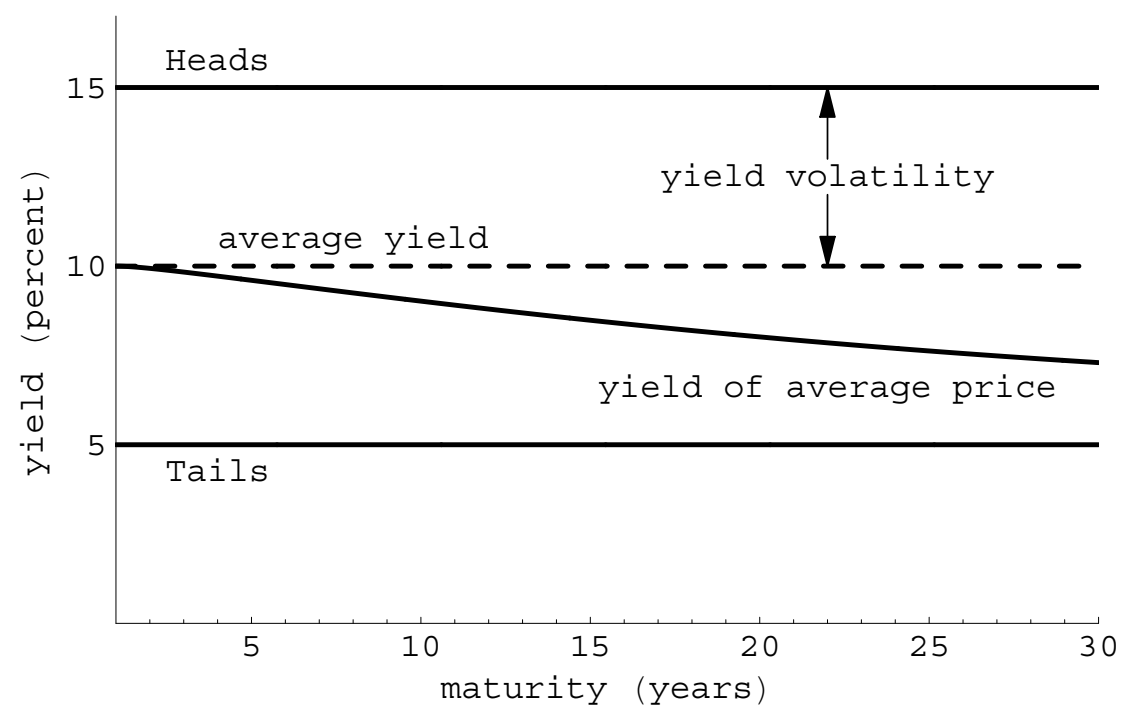

FiguRE 6. Zero coupon yield curves where $\bar{y}=0.15$ and $\delta^{y}=0.05$.

where $\cosh (x) \equiv\left(e^{x}+e^{-x}\right) / 2$ is the hyperbolic cosine of $x$. Finally, we can compute the continuously compounded yield from the average price as given in (6.1):

$$
\frac{-\log \left(\bar{p}_{n-1}\right)}{n-1}=\bar{y}_{n-1}-\frac{\log \left(\cosh \left((n-1) \delta_{n-1}^{y}\right)\right)}{n-1} .
$$

Equation (6.2) shows that the yield computed from the average price equals the average yield minus the convexity term. As long as there is uncertainty, the convexity term is positive: $\log (\cosh (x))>0$ for $|x|>0$. As a result, the yield computed from the average price is less than the average yield as long as there is uncertainty. ${ }^{29}$ Figure 7 illustrates the quadratic nature of the convexity term for values of $(n-1) \delta_{n-1}^{y}$ that are not too large. The solid line plots $\log (\cosh (x))$ and the dashed line plots the approximation $\frac{1}{2} x^{2}$ for $|x| \leq 1$. This approximation indicates that convexity depends on $\left(\delta_{n-1}^{y}\right)^{2}$, which you may recall is the variance of the yield.

The effect of convexity on the yield curve. To illustrate the effect of convexity on the yield curve, assume the price of risk is zero so that there is no risk premium. As a consequence, $p_{n}=p_{1} \bar{p}_{n-1}$. In this case the (pre-flip) yield on an $n$-period

\footnotetext{
${ }^{29}$ The limiting behavior of the convexity term is determined solely by the limiting behavior of the yield volatility:

$$
\lim _{n \rightarrow \infty} \frac{\log \left(\cosh \left((n-1) \delta_{n-1}^{y}\right)\right)}{n-1}=\lim _{n \rightarrow \infty}\left|\delta_{n-1}^{y}\right|
$$

if the latter limit exists. In the simplest case, where $\delta_{n-1}^{y}=\delta^{y}>0$ is constant, the limit of convexity term is simply $\delta^{y}$.
} 


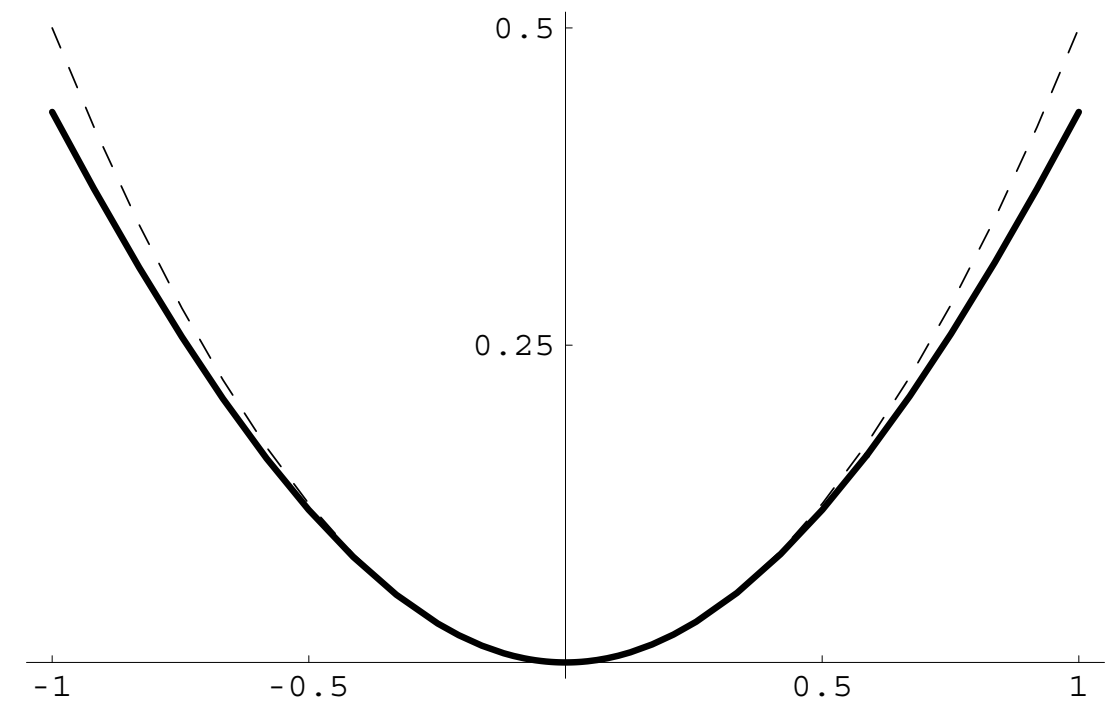

Figure 7 . The solid line plots the convexity term $\log (\cosh (x))$ and the dashed line plots the approximation $\frac{1}{2} x^{2}$ for $|x| \leq 1$.

bond can be written

$$
\begin{aligned}
y_{n} & =\frac{-\log \left(p_{n}\right)}{n} \\
& =\frac{-\log \left(p_{1} \bar{p}_{n-1}\right)}{n} \\
& =\left(\frac{1}{n}\right) y_{1}+\left(\frac{n-1}{n}\right)\left(\frac{-\log \left(\bar{p}_{n-1}\right)}{n-1}\right) \\
& =\underbrace{\frac{1}{n}\left(y_{1}+(n-1) \bar{y}_{n-1}\right)}_{\text {expectation }}-\underbrace{\frac{1}{n} \log \left(\cosh \left((n-1) \delta_{n-1}^{y}\right)\right)}_{\text {convexity }} .
\end{aligned}
$$

The last line of (6.3) shows the yield is a weighted average of the return on the one-period bond and the average yield of $(n-1)$-period bond next period minus a convexity-related term.

Recall the example from the previous section, where the current one-period yield equals the average long term yield, $y_{1}=\bar{y}_{n-1}=\bar{y}$, for all $n \geq 2$, and the yield volatility is constant, $\delta_{n-1}^{y}=\delta^{y}$. Then the yield on an $n$-period bond (i.e., the yield curve) is given by

$$
y_{n}=\bar{y}-\frac{1}{n} \log \left(\cosh \left((n-1) \delta^{y}\right)\right) .
$$

The yield curve starts at $\bar{y}$ for $n=1$ and declines steadily to an asymptote of $\bar{y}-\left|\delta^{y}\right| \cdot{ }^{30}$

\footnotetext{
${ }^{30}$ If the asymptotic yield were not at the minimum of its support, there would be arbitrage opportunities. See Dybvig, Ingersoll, and Ross (1996).
} 
Bond-price volatility and the risk premium. Thus far we have seen the effect of convexity on the shape of the yield curve. In order to examine the role of risk premia, we must return to the kind of risk that earns a premium-namely, bondprice volatility. Fortunately, we can express bond-price volatility in terms of bondyield volatility:

$$
\delta_{n-1}^{p}=\frac{p_{n-1}^{H}-p_{n-1}^{T}}{2}=e^{-(n-1) \bar{y}_{n-1}} \sinh \left(-(n-1) \delta_{n-1}^{y}\right),
$$

where $\sinh (x) \equiv\left(e^{x}-e^{-x}\right) / 2$ is the hyperbolic sine of $x$.

Now we need to derive an expression for long-term yields that allows us to constructively apply the expression for bond-price volatility. To this end, use Equation (4.12) to express (4.4) as $^{31}$

$$
p_{n}=\frac{\bar{p}_{n-1}-\lambda \delta_{n-1}^{p}}{1+r},
$$

where $-1<\lambda<1$. (The restriction on the range of $\lambda$ is necessary in order to keep the adjusted average price between $p_{n-1}^{H}$ and $p_{n-1}^{T}$.) We can write Equation (6.5) as

$$
p_{n}=p_{1}\left(\bar{p}_{n-1}-\lambda \delta_{n-1}^{p}\right),
$$

where $p_{1}=1 /(1+r)$ is the price of a one-period bond. Using (6.4), we can write (6.6) in terms of yields

$$
e^{-n y_{n}}=e^{-y_{1}} e^{-(n-1) \bar{y}_{n-1}}\left\{\cosh \left((n-1) \delta_{n-1}^{y}\right)+\lambda \sinh \left((n-1) \delta_{n-1}^{y}\right)\right\},
$$

or (takings logs and dividing by $-n$ )

$$
\begin{aligned}
& y_{n}=\overbrace{\frac{1}{n}\left(y_{1}+(n-1) \bar{y}_{n-1}\right)}^{\text {expectation }} \\
& -\overbrace{\frac{1}{n} \log (\overbrace{\cosh \left((n-1) \delta_{n-1}^{y}\right)}^{\text {convexity }}+\overbrace{\lambda \sinh \left((n-1) \delta_{n-1}^{y}\right)}^{\text {risk-related term premium }})}^{\text {premium }} .
\end{aligned}
$$

Equation (6.7) expresses the yield on an $n$-period bond at time zero in terms of the average yield of an $(n-1)$-period bond at time one and its volatility.

Figure 8 illustrates the roughly linear nature of the risk premium in (6.7) abstracting from the convexity term-for values of $(n-1) \delta_{n-1}^{y}$ that are not too large. The solid line plots the risk premium $\log (1+\lambda \sinh (x))$ and the dashed line plots the approximation $\lambda x$ for $|x| \leq 1$ (where $\lambda=-0.8$ ). This approximation along with the approximation illustrated in Figure 7 help us understand the overall shape of the yield curve. The risk premium is roughly linear in the risk while the convexity term is roughly quadratic in the risk. Therefore, risk premia dominate at the short end of the yield curve where $(n-1) \delta_{n-1}^{y}$ is small, while convexity plays

\footnotetext{
${ }^{31}$ See Appendix B for a derivation of the adjusted average price $\left(\bar{p}_{n-1}-\lambda \delta_{n-1}^{p}\right)$ using "adjusted probabilities."
} 
an important role at the long end where $(n-1) \delta_{n-1}^{y}$ is large. We will see this illustrated in the next section.

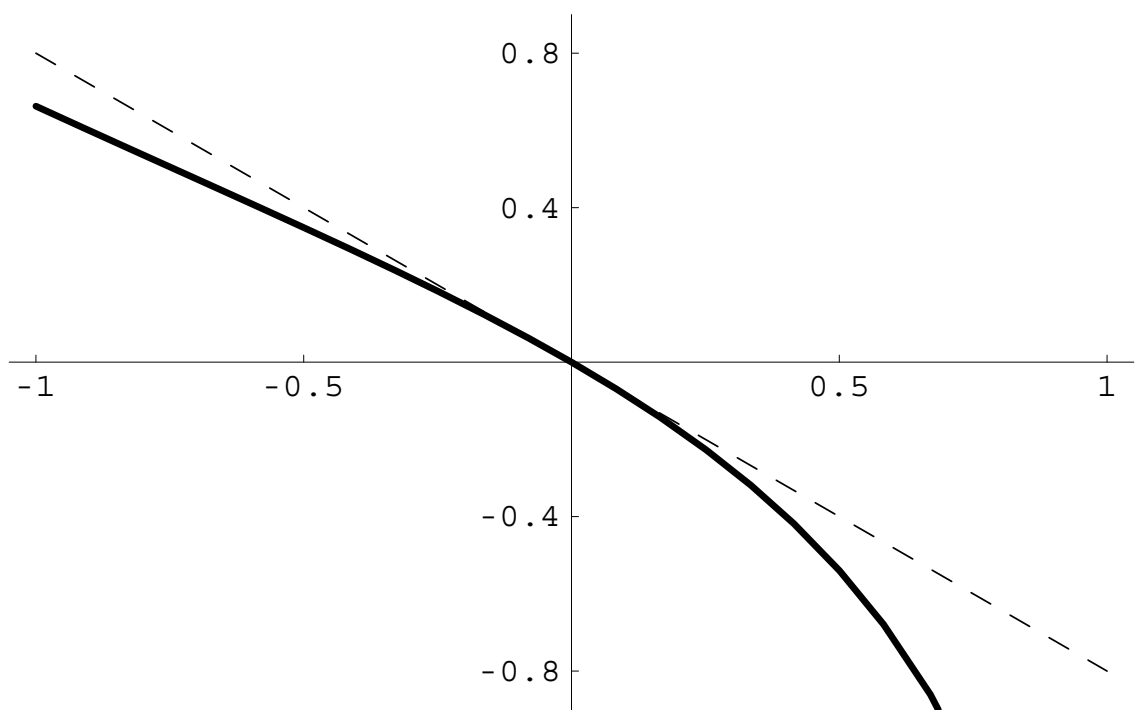

Figure 8. The solid line plots the risk-related term premium $\log (1+$ $\lambda \sinh (x))$ and the dashed line plots the approximation $\lambda x$ for $|x| \leq 1$ (where $\lambda=-0.8$ ).

\section{MOdeling THE ONE-PERIOD RETURN}

In the previous section, we showed how current bond yields are affected by uncertainty regarding future yields. In this section, we change perspective again and show how current bond yields are affected by uncertainty regarding the interest rate. However, it is much more convenient to use a continuously-compounded interest rate (denoted by $\rho$ ) rather than one-period interest rate $r$, which is computed with simple compounding. Instead of modeling uncertainty in terms of the yields on long-term bonds, we may wish to model it in terms of the (continuously-compounded) yield on one-period bonds. Let $\rho_{n}$ denote the continuously compounded return on a oneperiod bond that matures at time $t+n$. Let the average one-period interest rate and the volatility of the one-period interest rate be given by

$$
\bar{\rho}_{n}=\frac{\rho_{n}^{H}+\rho_{n}^{T}}{2} \quad \text { and } \quad \delta_{n}^{\rho}=\frac{\rho_{n}^{H}-\rho_{n}^{T}}{2} .
$$

Note that $\delta_{n}^{\rho}$ is a measure of the uncertainty of the future one-period rate as of time $t$ before the coin flip. Next period after the coin flip all uncertainty will have been resolved, and there will be no remaining uncertainty about where the one-period rate will be from then on. For the interest rate at time $t$, there is no uncertainty even before the coin flip: We have $\bar{\rho}_{0}=y_{1}$ and $\delta_{0}^{\rho}=0$.

Along each path (heads or tails) there is no uncertainty; therefore, after the coin flip, the long-term yields are simply averages of the subsequent series of one-period 
TABLE 14. Notation: Interest-rate uncertainty (continuouslycompounded interest rates)

\begin{tabular}{cl}
\hline \hline$\rho_{n}^{H}$ & $\begin{array}{l}\text { return on one-period bond that matures at time } t+n \text { if the } \\
\text { coin comes up heads }\end{array}$ \\
$\rho_{n}^{T}$ & $\begin{array}{l}\text { return on one-period bond that matures at time } t+n \text { if the } \\
\text { coin comes up tails }\end{array}$ \\
$\bar{\rho}_{n}$ & $\begin{array}{l}\text { average return on one-period bond that matures at time } t+n \\
\text { (pre-flip) }\end{array}$ \\
$\delta_{n}^{\rho}$ & interest-rate volatility \\
$\kappa$ & "shape" parameter for interest-rate volatility \\
$\sigma$ & "scale" parameter for interest-rate volatility \\
\hline \hline
\end{tabular}

rates along that path:

$$
y^{H}(1, n-1)=\frac{1}{n-1} \sum_{i=2}^{n} \rho_{i}^{H} \quad \text { and } \quad y^{T}(1, n-1)=\frac{1}{n-1} \sum_{i=2}^{n} \rho_{i}^{T} .
$$

We can compute $\bar{y}_{n-1}$ and $\delta_{n-1}^{y}$ from $y^{H}(1, n-1)$ and $y^{T}(1, n-1)$ as given by Equation (7.1):

$$
\bar{y}_{n-1}=\frac{\sum_{i=2}^{n} \bar{\rho}_{i}}{n-1} \quad \text { and } \quad \delta_{n-1}^{y}=\frac{\sum_{i=2}^{n} \delta_{i}^{\rho}}{n-1} .
$$

Using (7.2) (and $\bar{\rho}_{0}=y_{1}$ and $\delta_{0}^{\rho}=0$ ), we can write (6.7) as

$$
y_{n}=\overbrace{\frac{1}{n} \sum_{i=1}^{n} \bar{\rho}_{i}}^{\text {expectation }}-\frac{1}{n} \log (\overbrace{\cosh \left(\sum_{i=1}^{n} \delta_{i}^{\rho}\right)}^{\text {convexity }}+\overbrace{\lambda \sinh \left(\sum_{i=1}^{n} \delta_{i}^{\rho}\right)}^{\text {risk-related term premium }}) .
$$

Using (7.3), we can model the term structure in terms of $(i)$ the expected path of the one-period return $\left\{\bar{\rho}_{i}\right\},(i i)$ the uncertainty of the one-period return $\left\{\delta_{i}^{\rho}\right\}$, and (iii) the price of risk $\lambda$.

Let us begin by assuming the volatility of the one-period return has the following functional form:

$$
\delta_{n}^{\rho}=\sigma \sqrt{\frac{1-e^{-2 \kappa(n-1)}}{2 \kappa}},
$$

where $\kappa>0$ is the "shape" parameter and $\sigma$ is the "scale" parameter. The limiting shape is $\lim _{\kappa \rightarrow 0} \delta_{n}^{\rho}=\sigma \sqrt{n-1}$. For $\kappa>0$, the volatility has a limiting value as $n$ increase without bound: $\lim _{n \rightarrow \infty} \delta_{n}^{\rho}=\sigma / \sqrt{2 \kappa}$. Figure 9 plots $\delta_{n}^{\rho}$ and $-\delta_{n}^{\rho}$ using (7.4) with parameter values $\sigma=0.01$ and $\kappa=0.01$. 


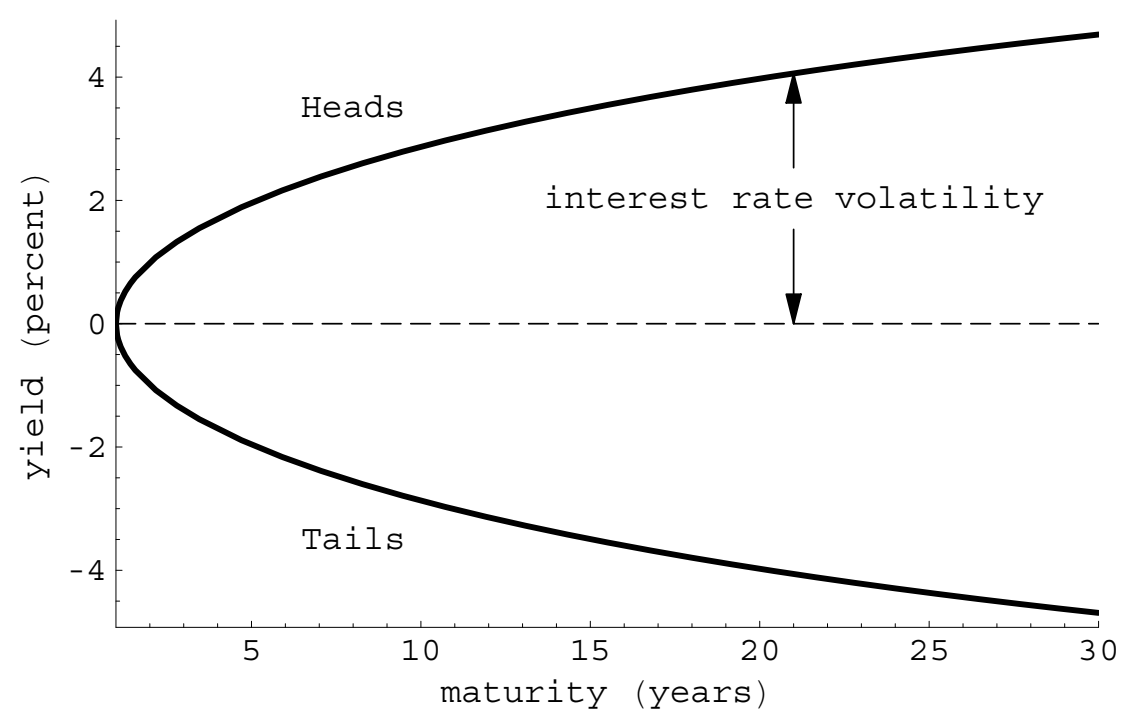

FIGURE 9. The volatility of the risk-free return on one-period bonds.

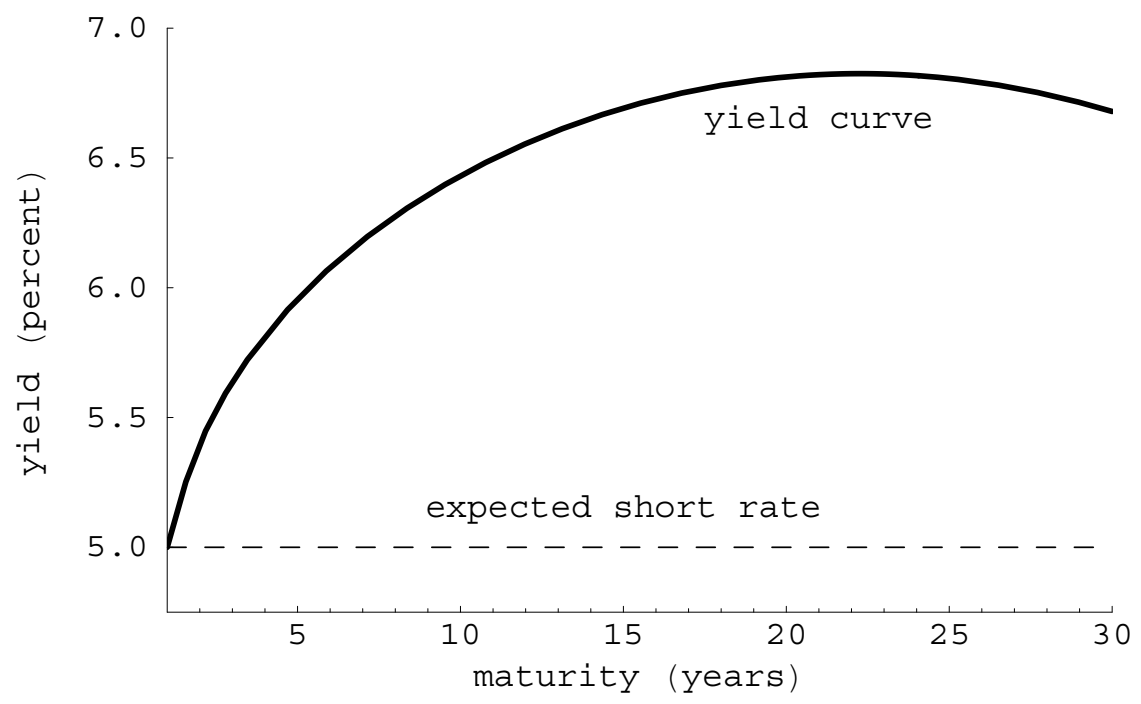

Figure 10. The zero-coupon yield curve. The expected one-period return is constant at 5 percent.

With this volatility function, we can build a model of the current yield curve by making assumptions about the expected path of the one-period return and the price of risk. A yield curve is shown in Figure 10, using the volatility function from Figure 9 , where $\bar{\rho}_{n}=0.05$ and $\lambda=-0.8$. Notice the sign of $\lambda$. Since the volatility of the interest rate is positive and bond prices go down when the interest rate goes up, the price of risk must be negative in order for the risk premium to be positive. The 
effect of convexity is evident: The zero-coupon yield curve reaches its maximum at 22 years and slopes downward beyond that point.

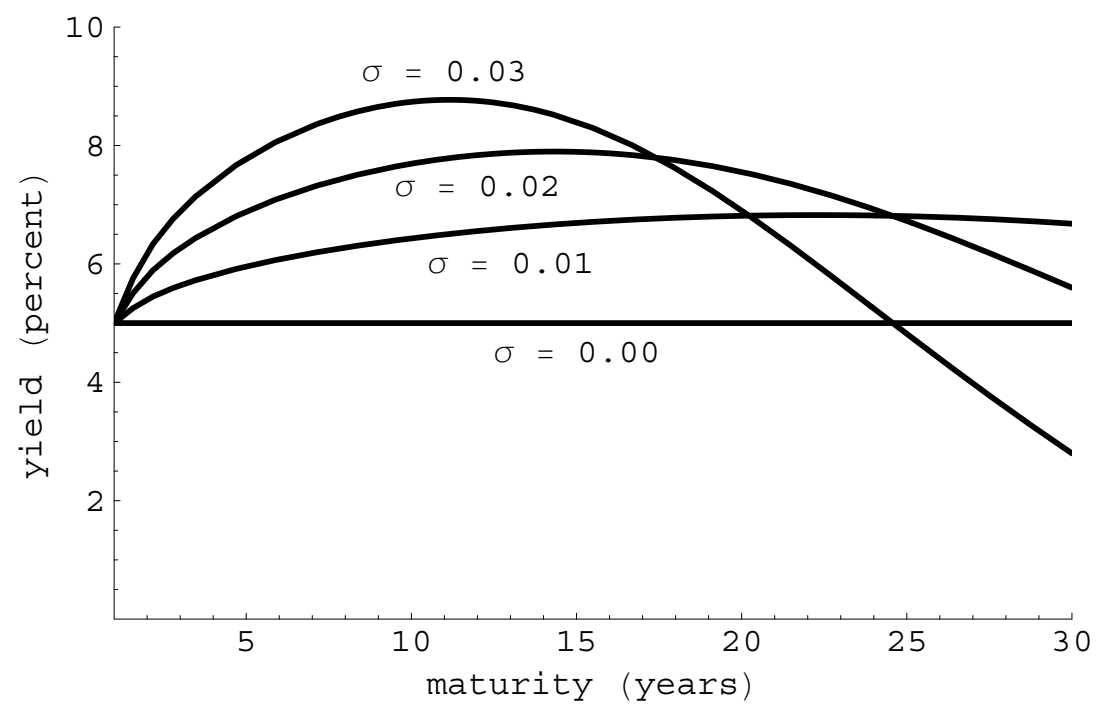

FIGURE 11. Increasing the volatility of the interest rate increase the curvature of the zero-coupon yield curve.

What happens to the yield curve when uncertainty about the future path of the short rate increases, holding the average path fixed? The answer can be found in Figure 11. With no volatility $(\sigma=0)$, the yield curve is flat, reflecting only the expectations component. As the volatility parameter $\sigma$ increases, the curvature of the yield curve increases. The slope of the yield curve at the short end increases because the risk premium increases, while the slope at the long end decreases because of the increased convexity.

If Figure 12 we show the effect of changing the price of risk. When the price of risk is zero $(\lambda=0)$, the convexity effect causes the yield curve to slope downward. As the magnitude (i.e., the absolute value) of the price of risk increases, the riskpremium component increases, which increase the average slope of the yield curve.

Now let us consider varying the path of the expected one-period yields, $\left\{\bar{\rho}_{i}\right\}$. One simple way to characterize the path is to assume that the one-period yield will revert over time to some long-run average value. We can parameterize such a path as follows:

$$
\bar{\rho}_{n}=e^{-k(n-1)} y_{1}+\left(1-e^{-k(n-1)}\right) \theta,
$$

where $\theta$ is the long-run average and $k \geq 0$ is the speed of mean reversion. According to (7.5), $\bar{\rho}_{n}$ is an average of the current one-period yield and the long run average yield. If $k=0$, there is no mean reversion and we never forecast the one-period return to change $\left(\bar{\rho}_{n}=y_{1}\right.$ for all $\left.n \geq 1\right)$. For $k>0$, the weights change with the forecast horizon so that in the limit as $n$ grows without bound, $\lim _{n \rightarrow \infty} \bar{\rho}_{n}=\theta$. In Figure 13 three paths are shown with different values for the mean-reversion 


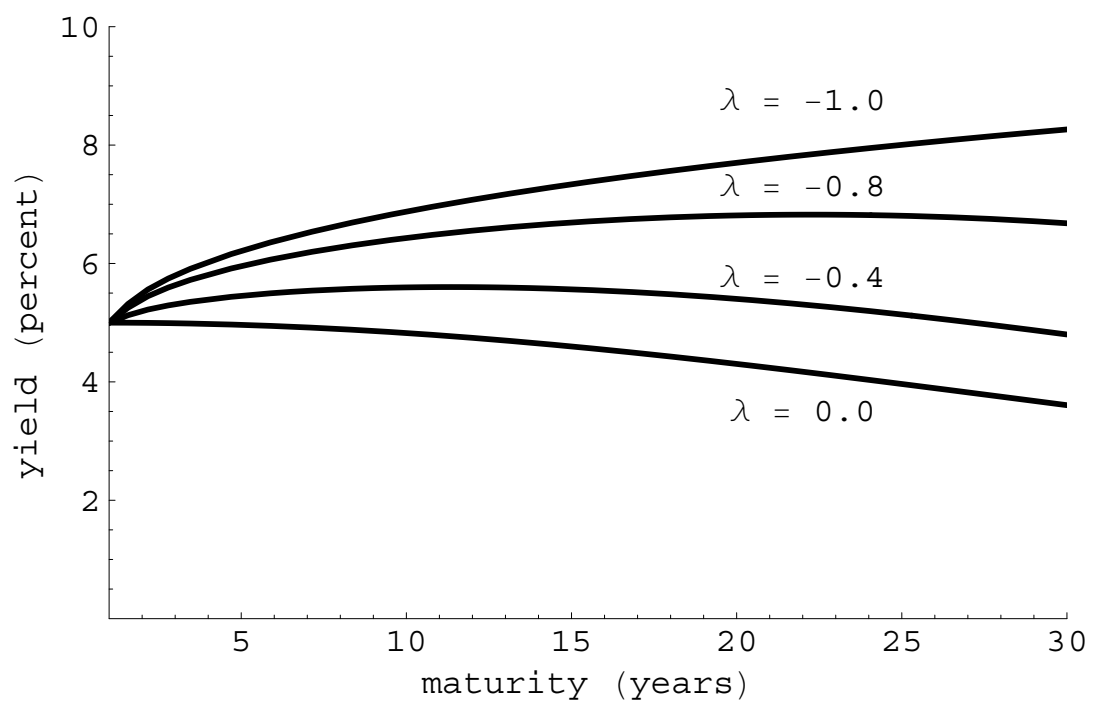

FiguRE 12. The effect of the price of risk on the zero-coupon yield curve.

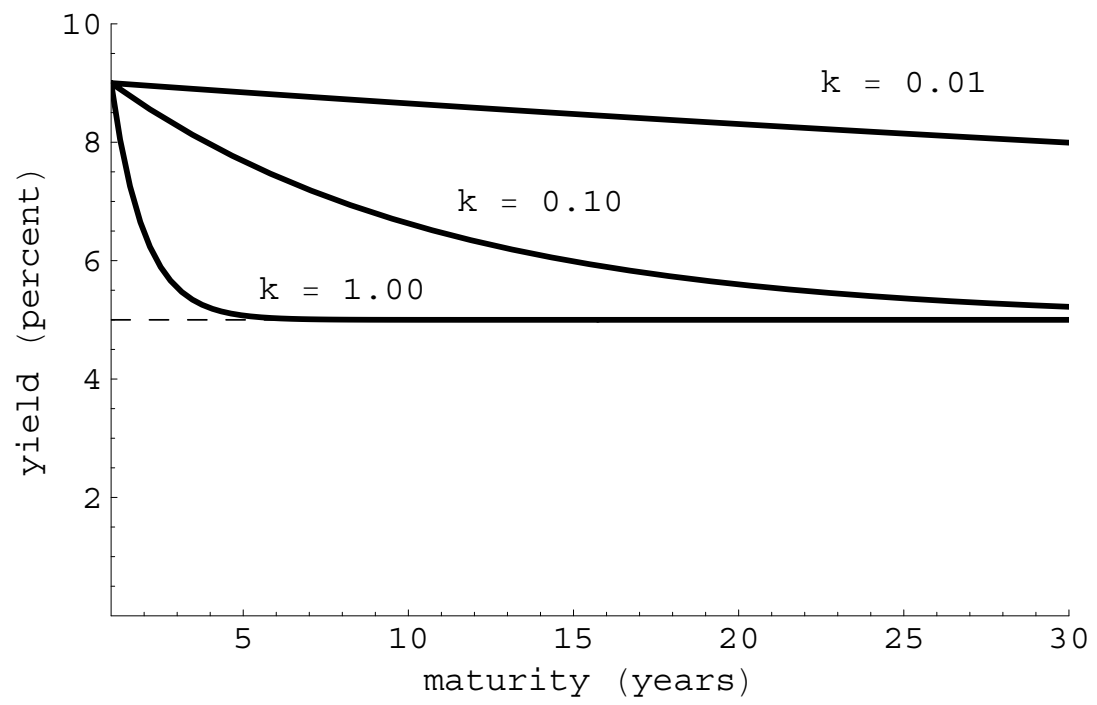

FiguRE 13. Expected future interest rate paths. The paths differ by the speed of mean reversion as parameterized by $k$.

parameter. All three paths have $y_{1}=0.09$ and $\theta=0.05$. Figure 14 shows the effect of varying the current one-period yield on the yield curve, where $k=0.08$. For low values of $y_{1}$, the yield curve slopes upward (at least for maturities less than 20 years). But for high values of $y_{1}$ the strong expectations component overwhelms the risk-premium component so that the yield curve slopes downward. At some intermediate values of $y_{1}$, the yield curve is humped at the short end, where the 


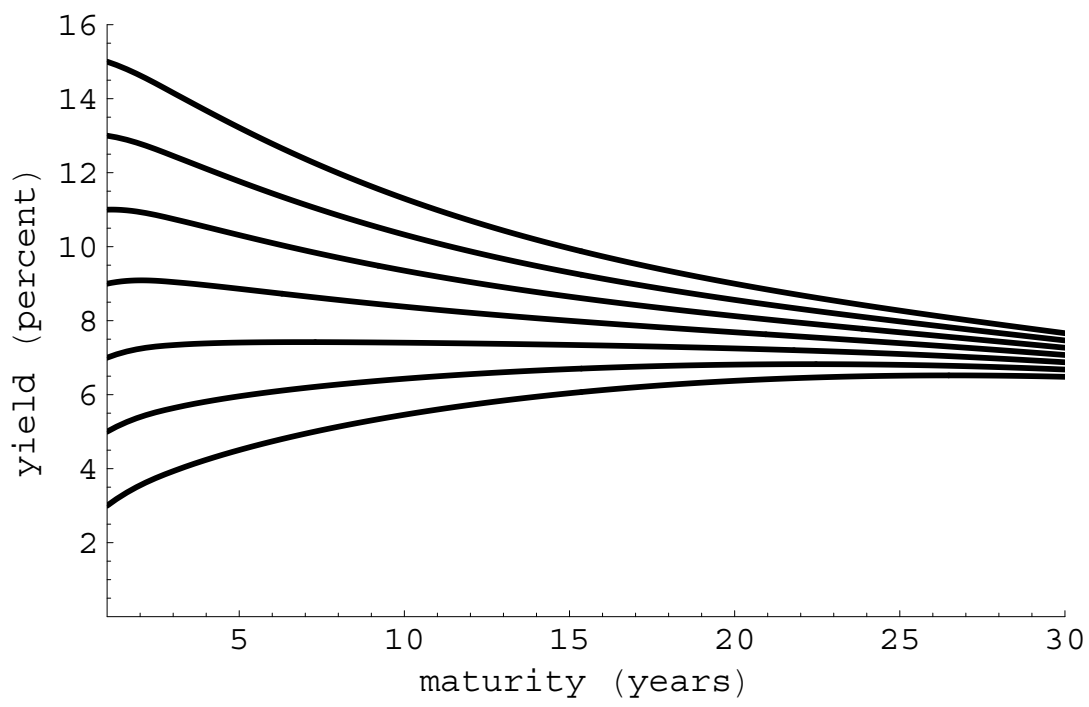

Figure 14. The effect of varying the current one-period yield on the yield curve, where $k=0.08$.

risk-premium component dominates at first and then the expectations component (along with the convexity component) dominates.

\section{ForWARD RATES AND THE EXPECTATIONS HYPOTHESIS}

Forward rates. If you sell an $(n-1)$-period bond today, you will receive $p(t, n-1)$ today and you will have to pay back one dollar at time $t+n-1$. In this example, you raised $p(t, n-1)$ dollars by selling $(n-1)$-period bonds, and you will pay back $1 / p(t, n-1)$ dollars per dollar raised. Table 16 shows the cash flows associated with rasing $x$ dollars today by selling some $(n-1)$-period bonds.

TABLE 15. Notation: Forward rates

\begin{tabular}{c}
\hline$f(t, n)$ or $f_{n} \quad n$-period forward rate at time $t$ (continuously-compounded) \\
\hline \hline
\end{tabular}

TABLE 16. Net cash flows from raising $x$ dollars by selling some $(n-1)$-period bonds.

\begin{tabular}{cc}
\hline$\frac{\text { Net cash flows }}{\text { Today (time } t)}$ & $\frac{\text { Later }(\text { time } t+n-1)}{x}$ \\
\hline \hline
\end{tabular}

Suppose you purchase an $n$-period bond today and finance the entire purchase by selling $(n-1)$-period bonds. The net cash flows associated with this trade are 
shown in Table 17. This strategy results in cash flows that amount to lending $p(t, n) / p(t, n-1)$ at time $t+n-1$ and receiving 1 at time $t+n$ one period later. Therefore, this strategy produces a risk-free one-period return from $t+n-1$ to $t+n$ of

$$
f(t, n)=-\log \left(\frac{p(t, n)}{p(t, n-1)}\right)
$$

where $f(t, n)$ is the (continuously-compounded) forward rate.

TABLE 17. Net cash flows from buying an $n$-period bond today and financing it by selling $(n-1)$-period bonds.

\begin{tabular}{|c|c|c|}
\hline \multicolumn{3}{|c|}{ Net cash flows } \\
\hline Today (time $t$ ) & Later (time $t+n-1)$ & Maturity (time $t+n)$ \\
\hline 0 & $-p(t, n)\left(\frac{1}{p(t, n-1)}\right)$ & 1 \\
\hline
\end{tabular}

Using (8.1) repeatedly, we can express today's bond prices in terms of today's forward rates:

$$
p(t, n)=e^{-f(t, 1)} \times e^{-f(t, 2)} \times \cdots \times e^{-f(t, n-1)} \times e^{-f(t, n)} .
$$

Comparing (8.2) with $p(t, n)=e^{-n y(t, n)}$, we see that forward rates and yields are related as follows:

$$
y(t, n)=\frac{1}{n} \sum_{i=1}^{n} f(t, i)
$$

We can use (8.3) to show

$$
\begin{aligned}
f(t, n) & =n y(t, n)-(n-1) y(t, n-1) \\
& =y(t, n)+(n-1)(y(t, n)-y(t, n-1)) .
\end{aligned}
$$

The second line of (8.4) shows that if the yield curve is rising then the forward rate is above the yield curve and vice-versa:

$$
f(t, n) \gtreqless y(t, n) \Longleftrightarrow y(t, n) \gtreqless y(t, n-1) .
$$

We can use the first line of (8.4) along with (7.3) to explore the relation between forward rates and expected future spot rates:

$$
f_{n}=\bar{\rho}_{n}+\log \left(\frac{\cosh \left(s_{n-1}\right)+\lambda \sinh \left(s_{n-1}\right)}{\cosh \left(s_{n-1}+\delta_{n}^{\rho}\right)+\lambda \sinh \left(s_{n-1}+\delta_{n}^{\rho}\right)}\right),
$$

where $s_{n-1}=\sum_{i=1}^{n-1} \delta_{i}^{\rho}$. Note that if there is no uncertainty about $\rho_{n}$ (i.e., if $\left.\delta_{n}^{\rho}=0\right)$, then $f_{n}=\bar{\rho}_{n} \cdot 32$

\footnotetext{
${ }^{32}$ The forward rate $f_{n}$ refers to the borrowing/lending rate that can be locked in from time $n-1$ to time $n$. Next period, after the coin flip, the forward rate that refers to that period of time will be either

$$
f_{n-1}^{H}=-\log \left(\frac{p_{n-1}^{H}}{p_{n-2}^{H}}\right)=\rho_{n}^{H} \quad \text { or } \quad f_{n-1}^{T}=-\log \left(\frac{p_{n-1}^{T}}{p_{n-2}^{T}}\right)=\rho_{n}^{T} .
$$
}


The expectations hypothesis. Using (8.3), the yield on a bond at time zero can be expressed in terms of the forward rates at time zero:

$$
y_{n}=\frac{1}{n} \sum_{i=1}^{n} f_{i},
$$

where $f_{n}=-\log \left(p_{n} / p_{n-1}\right)$. The strong form of the expectations hypothesis says that forward rates equal expected future one-period returns: ${ }^{33}$

$$
f_{n}=\bar{\rho}_{n} \quad \text { for all } n \geq 1 .
$$

Thus the strong form of the expectations hypothesis implies

$$
y_{n}=\frac{1}{n} \sum_{i=1}^{n} \bar{\rho}_{i} .
$$

Comparing (8.7) with (7.3) we see that the risk-related term in (7.3) is identically zero, which is equivalent to

$$
\cosh \left(\sum_{i=1}^{n} \delta_{i}^{\rho}\right)+\lambda \sinh \left(\sum_{i=1}^{n} \delta_{i}^{\rho}\right)=1 \quad \text { for all } n \geq 1 .
$$

For $|\lambda|<1$, there are two solutions to $\cosh (x)+\lambda \sinh (x)=1$ :

$$
x=0 \quad \text { and } \quad x=\log (1-\lambda)-\log (1+\lambda) .
$$

This means there can be only one non-zero $\delta_{n}^{\rho}$ absent arbitrage opportunities. In Appendix $\mathrm{C}$ we show that (8.7) can be satisfied more generally if there are two sources of uncertainty (two coin flips).

\section{The TAXABlE-TAX-EXempt YIELD SPREAD}

Thus far in our study of bond prices and yields we have implicitly assumed there are no taxes. Now we will assume there are two types of default-free zero-coupon bonds: taxable and tax-exempt. One can compute the "implied marginal tax rate" from the yields on the two types of bonds:

$$
\text { implied marginal tax rate }=\frac{(\text { taxable yield })-(\text { tax-exempt yield })}{\text { taxable yield }} .
$$

The naive view is that if there were a constant marginal tax rate $\tau$, then the implied marginal tax rate ought to equal $\tau$ at all maturities. But in fact the implied marginal tax rate declines with maturity out to at least 30 years. A number of reasons have been put forth to explain this fact, but none has done so completely.

Convexity can help explain why the spread between taxable yields and taxexempt yields narrows as the maturity increases. For simplicity, assume $(i)$ there is

Therefore $\bar{f}_{n-1}=\bar{\rho}_{n}$ and $\delta_{n-1}^{f}=\delta_{n}^{\rho}$. Thus, in this simple setting, specifying the path of expected one-period risk-free returns and their volatilities is the same as specifying the path of expected forward rates and their volatilities.

${ }^{33}$ Equation (7.3) satisfies the weak form of the expectations hypothesis, where the term premium is fixed. See Cox, Ingersoll, Jr., and Ross (1981) on Jensen's inequality as applied to the term structure and Campbell (1986) on linearizations of these nonlinear relations. 
a single, constant marginal tax rate and (ii) there are no opportunities for deferring taxes. ${ }^{34}$ For short-term interest rates, the absence of arbitrage opportunities implies tax-exempt interest rate $=(1-$ tax rate $) \times$ taxable interest rate.

This relation between the short-term interest rates implies the following relation between their variances:

$\operatorname{Var}($ tax-exempt interest rate $)=(1-\text { tax rate })^{2} \times \operatorname{Var}($ taxable interest rate $)$.

Since the tax rate is between zero and one, the variance of the tax-exempt shortterm rate is less than the variance of the short-term taxable rate:

$$
\operatorname{Var}(\text { tax-exempt interest rate })<\operatorname{Var}(\text { taxable interest rate }) \text {. }
$$

Recall that the size of the convexity effect on longer-term yields depends on the size of the variance of the short-term interest rate. The smaller variance of the taxexempt interest rate produces a smaller convexity effect, resulting in less curvature for the tax-exempt yield curve than for the taxable yield curve. In other words, long term tax-exempt yields are not pulled down by as much as the higher taxable yields. As a result, the spread between the two curves narrows as maturity increases.

TABLE 18. Notation: Taxable bonds

\begin{tabular}{|c|c|}
\hline$p^{\tau}(t, n)$ or $p_{n}^{\tau}$ & value at time $t$ of an $n$-period taxable bond \\
\hline$r^{\tau}(t)$ or $r^{\tau}$ & $\begin{array}{l}\text { one-period risk-free taxable interest rate (simple compound- } \\
\text { ing) }\end{array}$ \\
\hline$p_{n-1}^{\tau H}$ & $\begin{array}{l}\text { value next period of an }(n-1) \text {-period taxable bond if the } \\
\text { coin comes up heads }\end{array}$ \\
\hline$p_{n-1}^{\tau T}$ & $\begin{array}{l}\text { value next period of an }(n-1) \text {-period taxable bond if the } \\
\text { coin comes up tails }\end{array}$ \\
\hline $\bar{p}_{n-1}^{\tau}$ & $\begin{array}{l}\text { average value next period of an }(n-1) \text {-period taxable bond } \\
\text { (pre-flip) }\end{array}$ \\
\hline$\delta_{n-1}^{p^{\tau}}$ & volatility taxable bond price (amount of risk) \\
\hline$a_{n-1}^{\tau}$ & taxable-bond adjustment term (risk premium) \\
\hline$\xi_{n}$ & $\begin{array}{l}\text { return on an } n \text {-period taxable bond that mature at time } t+n \\
\text { (continuously-compounded one-period taxable interest rate) }\end{array}$ \\
\hline
\end{tabular}

Taxable vs. tax-exempt bonds. Let $p(t, n)$ denote the value of an $n$-period tax-exempt bond and $p^{\tau}(t, n)$ denote the value of an $n$-period taxable bond. For simplicity, we will assume there is a single constant marginal tax rate $\tau$, where $0 \leq \tau<1$. Here is how the idealized tax system works. If one owns an $n$-period

\footnotetext{
${ }^{34}$ This simplified tax system abstracts from some important features of the actual tax system.
} 
bond at time $t$, then one pays taxes on the capital gain at time $t+1$. The tax liability is

$$
\tau\left\{p^{\tau}(t+1, n-1)-p^{\tau}(t, n)\right\} .
$$

(If there is a capital loss, the tax liability is negative, and one gets a refund.) The after-tax net cash flows associated with buying a taxable bond and selling it next period are shown in Table 19.

TABLE 19. Net after-tax cash flows from buying an $n$-period taxable bond today and selling it next period.

\begin{tabular}{ll}
\hline \hline Today (time $t)$ & Net cash flows \\
$\frac{-p^{\tau}(t, n)}{(1-\tau) p^{\tau}(t+1, n-1)+\tau p^{\tau}(t, n)}$ \\
\hline \hline
\end{tabular}

Consider the following trading strategy: Buy a taxable bond and finance it with one-period tax-exempt borrowing. The net cash flows for this trading strategy are shown in Table 20. If there were no uncertainty about the price of the taxable bond next period, the net cash flow next period must be zero in order to avoid arbitrage opportunities. For a one-period taxable bond, this is always the case since $p^{\tau}(0, t-1) \equiv 1$. Therefore,

$$
p^{\tau}(t, 1)=\frac{1-\tau}{1+r(t)-\tau} .
$$

Now we can define the one-period taxable risk-free interest rate as the return on the one-period taxable bond:

$$
r^{\tau}(t)=\frac{1-p^{\tau}(t, 1)}{p^{\tau}(t, 1)}=\frac{r(t)}{1-\tau} .
$$

For longer-term taxable bonds, the absence-of-arbitrage condition (when there is no uncertainty) can be expressed in a way that is strictly parallel to the condition for tax-exempt bonds: Today's price is the present value of next period's price using the taxable interest rate:

$$
p^{\tau}(t, n)=\frac{p^{\tau}(t+1, n-1)}{1+r^{\tau}(t)} .
$$

This pricing formula guarantees the net after-tax return on taxable bonds equals the net return on tax-exempt bonds.

Uncertainty and the absence of arbitrage opportunities. Let us adopt the same framework for uncertainty as for tax-exempt bonds: There are two possible outcomes for the price of a taxable bond next period, $p_{n-1}^{\tau H}$ and $p_{n-1}^{\tau T}$. The outcome is determined by the same coin flip that determines the outcome for tax-exempt 
TABLE 20. Net after-tax cash flows from buying an $n$-period taxable bond today and financing it with one-period tax-exempt borrowing.

\begin{tabular}{|c|c|}
\hline \multicolumn{2}{|r|}{ Net cash flows } \\
\hline Today (time $t$ ) & Next period (time $t+1)$ \\
\hline 0 & $(1-\tau) p^{\tau}(t+1, n-1)+\tau p^{\tau}(t, n)-(1+r) p^{\tau}(t, n)$ \\
\hline
\end{tabular}

bonds. The average price and volatility of a taxable bond's price next period are given by

$$
\bar{p}_{n-1}^{\tau}=\frac{p_{n-1}^{\tau H}+p_{n-1}^{\tau T}}{2} \quad \text { and } \quad \delta_{n-1}^{p^{\tau}}=\frac{p_{n-1}^{\tau H}-p_{n-1}^{\tau T}}{2}
$$

Today's price for a taxable bond can be written as the present value of the adjusted average price:

$$
p_{n}^{\tau}=\frac{\bar{p}_{n-1}^{\tau}+a_{n-1}^{\tau}}{1+r^{\tau}}
$$

where $r^{\tau}=r(t)^{\tau}$. If we form a risk-free portfolio of two taxable bonds and finance it by borrowing at the taxable risk-free interest rate, we can reveal the following absence of arbitrage condition:

$$
\frac{a_{n-1}^{\tau}}{\delta_{n-1}^{p^{\tau}}}=\frac{a_{m-1}^{\tau}}{\delta_{m-1}^{p^{\tau}}},
$$

where $m$ and $n$ are the maturities of the two bonds. We see that taxable bonds must all share the same price of risk. But is it the same as the price of risk for tax-exempt bonds?

To answer this question, form a risk-free portfolio by buying one tax-exempt bond and selling some taxable bonds. The cost of the portfolio today is $p_{n}+b^{*} p_{m}^{\tau}$ and the after-tax value of the portfolio next period is

$$
\pi^{*}=\bar{p}_{n-1}+b^{*}\left((1-\tau) \bar{p}_{m-1}^{\tau}+\tau p_{m}^{\tau}\right)
$$

where $b^{*}$ is the hedge ratio computed from the after-tax payments next period:

$$
b^{*}=-\left(\frac{\delta_{n-1}^{p}}{(1-\tau) \delta_{m-1}^{p^{\tau}}}\right) .
$$

If we finance this risk-free portfolio by borrowing at the tax-exempt risk-free rate, the absence-of-arbitrage condition is

$$
\pi^{*}-(1+r)\left(p_{n}+b^{*} p_{m}^{\tau}\right)=0
$$

which can be reduced to

$$
\lambda=\frac{a_{n-1}}{\delta_{n-1}^{p}}=\frac{a_{m-1}^{\tau}}{\delta_{m-1}^{p^{\tau}}} .
$$

In other words, the price of risk is the same for all bonds, both taxable and taxexempt. Thus we may write $a_{n-1}^{\tau}=\lambda \delta_{n-1}^{p^{\tau}}$ and, consequently we can write (9.2) 
as

$$
p_{n}^{\tau}=p_{1}^{\tau}\left(\bar{p}_{n-1}^{\tau}-\lambda \delta_{n-1}^{p^{\tau}}\right) .
$$

Equation (9.3) is the same as (6.6) except that everything is expressed in before-tax terms. We can also express (9.2) in terms of expected returns:

$$
\frac{\bar{p}_{n-1}^{\tau}-p_{n}^{\tau}}{p_{n}^{\tau}}=r^{\tau}+\lambda\left(\frac{\delta_{n-1}^{p^{\tau}}}{p_{n}^{\tau}}\right) .
$$

Equation (9.4) says that the expected (before-tax) return on a taxable bond equals the taxable risk-free rate plus a risk premium that is the product of the amount of (before tax) risk and the (universal) price of risk.

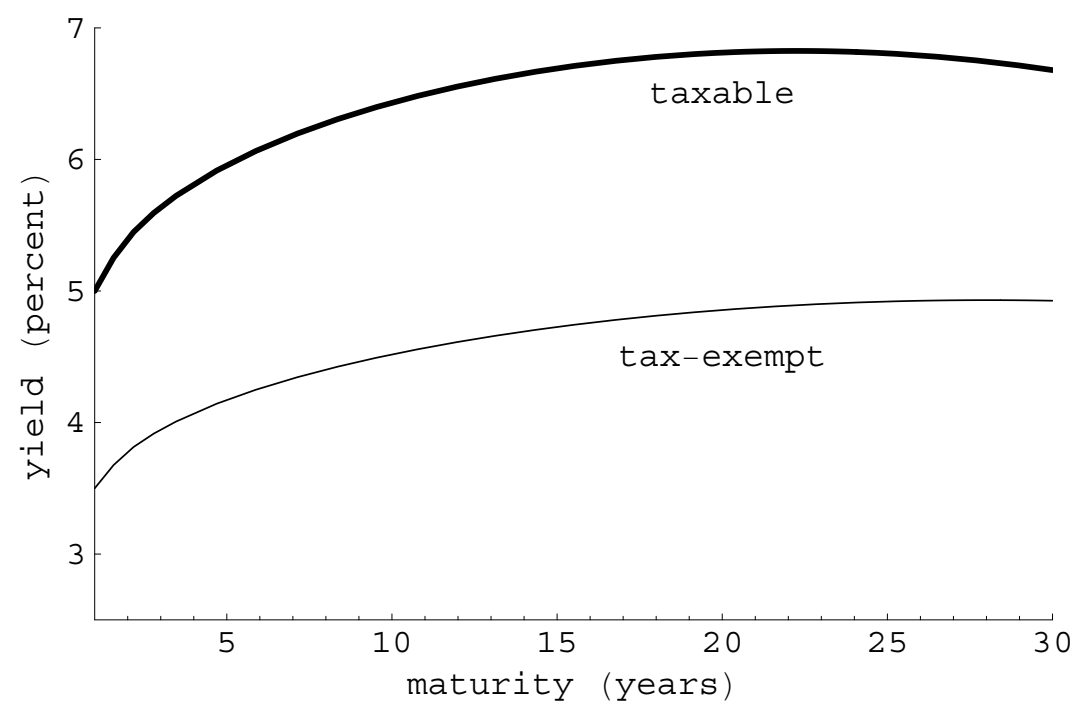

FiguRE 15. Taxable and tax-exempt zero-coupon yield curves.

Modeling the short-term taxable interest rate. Let $\xi_{n}^{H}$ and $\xi_{n}^{T}$ denote the before-tax, continuously-compounded returns on a one-period taxable bond that matures at time $n$. Also let $\bar{\xi}_{n}$ denote the average one-period taxable return and let $\delta_{n}^{\xi}$ denote its volatility. Then (9.3) can be expressed as

$$
y_{n}^{\tau}=\frac{1}{n} \sum_{i=1}^{n} \bar{\xi}_{i}-\frac{1}{n} \log \left(\cosh \left(\sum_{i=1}^{n} \delta_{i}^{\xi}\right)+\lambda \sinh \left(\sum_{i=1}^{n} \delta_{i}^{\xi}\right)\right),
$$

where $y_{n}^{\tau}$ denote the before-tax yield on an $n$-period taxable bond.

All that remains is to establish the link between $\rho$ and $\xi$. Our expressions for the term structure are written in terms of continuously compounded rates rather than simple rates as in (9.1). We can simplify the subsequent exposition without noticeably affecting the numerical results by using the approximation

$$
y_{1}=(1-\tau) y_{1}^{\tau} \text {. }
$$




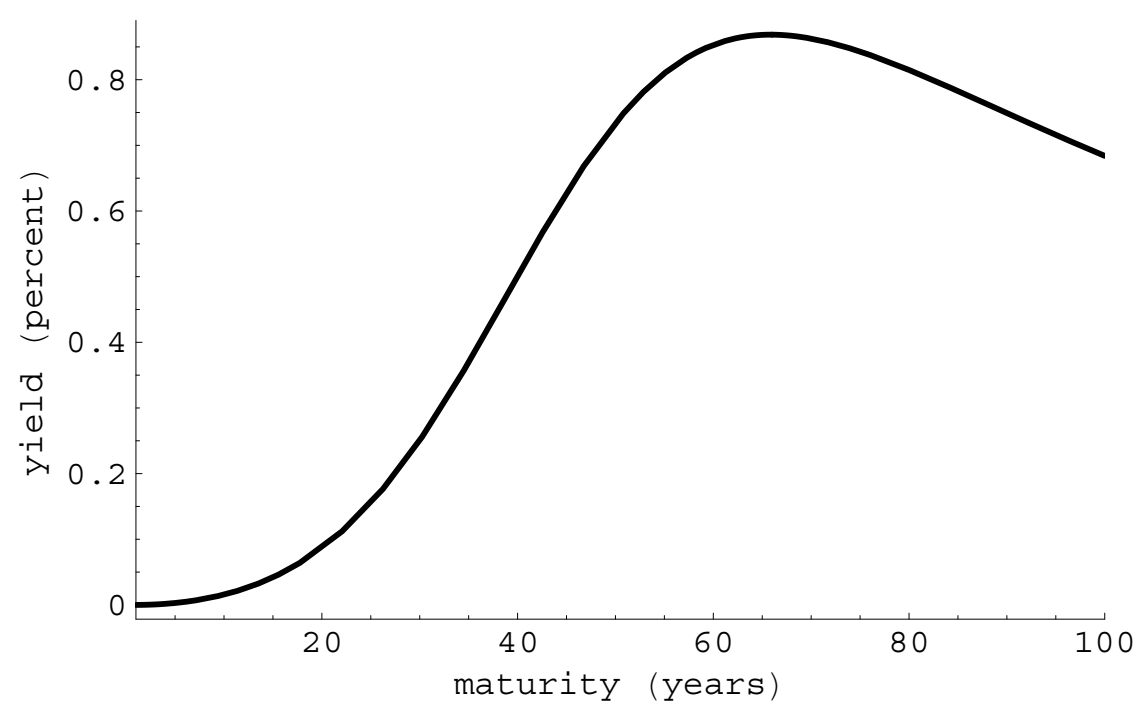

FiguRE 16. The tax-adjusted yield spread out to 100 years.

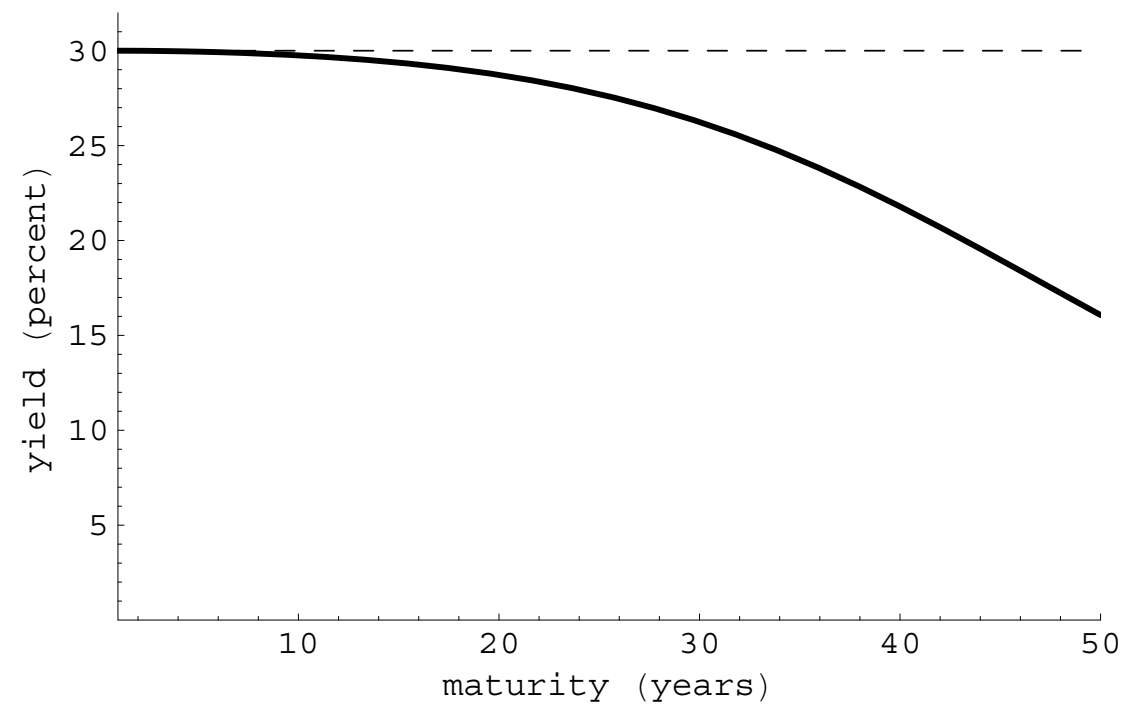

Figure 17. The implied tax rate out to 50 years. The actual tax rate is 30 percent.

Similar approximations produce

$$
\rho_{n}^{H}=(1-\tau) \xi_{n}^{H} \quad \text { and } \quad \rho_{n}^{T}=(1-\tau) \xi_{n}^{T},
$$

which in turn imply

$$
\bar{\rho}_{i}=(1-\tau) \bar{\xi}_{i} \quad \text { and } \quad \delta_{i}^{\rho}=(1-\tau) \delta_{i}^{\xi} .
$$


We are now in a position to show how the two yield curves are related. In Figure 15, we show taxable and tax-exempt zero-coupon yield curves where the taxable curve is the same as above and the marginal tax rate is 30 percent. The tax-adjusted yield spread is given by

$$
\begin{aligned}
& y_{n}-(1-\tau) y_{n}^{\tau}=\frac{(1-\tau) \log \left(\cosh \left(\sum_{i=1}^{n} \delta_{i}^{\xi}\right)+\lambda \sinh \left(\sum_{i=1}^{n} \delta_{i}^{\xi}\right)\right)}{n} \\
& -\frac{\log \left(\cosh \left((1-\tau) \sum_{i=1}^{n} \delta_{i}^{\xi}\right)+\lambda \sinh \left((1-\tau) \sum_{i=1}^{n} \delta_{i}^{\xi}\right)\right)}{n} .
\end{aligned}
$$

We have expressed the tax-adjusted spread in terms of the volatility of the taxable one-period return. The yield spread is zero if there is no uncertainty or if the tax rate is zero. ${ }^{35}$ Figure 16 shows the tax-adjusted yield spread out to 100 years. The naive view is that the tax-adjusted yield spread is zero for all maturities even when there is uncertainty. Our analysis of the yield curve using the absence-of-arbitrage conditions shows otherwise. Recall the implied marginal tax-rate is computed as follows: $\left(y_{n}^{\tau}-y_{n}\right) / y_{n}^{\tau}$. The implied marginal tax-rate is shown in Figure 17 out to 50 years. Note that the implied rate starts at 30 percent and declines steadily.

\section{Summary}

The yield curve is often used as a tool for prognostication. The core idea is that the current long-term yields can tell us where future short-term yields will be. Broadly speaking, this is known as the expectations hypothesis. This hypothesis presumes that changes in the shape of the yield curve are driven largely by changes in expectations of future rates. However other forces that involve uncertainty, including time-varying risk premia and convexity, are also important. Consequently, the expectations hypothesis fails to explain a number of important features of the yield curve.

A deeper understanding of the forces that shape the yield curve is obtained by examining the conditions that guarantee the absence of arbitrage opportunities. When there is no uncertainty, no-arbitrage conditions completely determine the relation between today's yield curve and future interest rates. But when uncertainty is introduced, the link between today's yield curve and future interest rates is substantially weakened. Yet even in this case, the conditions that guarantee the absence of arbitrage opportunities give the relation useful structure that provides a foundation

\footnotetext{
${ }^{35}$ In the limit as $n$ goes to infinity, the spread goes to zero if the appropriate limits exist, since

$$
\begin{aligned}
\lim _{n \rightarrow \infty}(1-\tau) y_{n}^{\tau} & =\lim _{n \rightarrow \infty}(1-\tau)\left(\frac{1}{n} \sum_{i=1}^{n} \bar{\xi}_{i}-\left|\sum_{i=1}^{n} \delta_{i}^{\xi}\right|\right) \\
& =\lim _{n \rightarrow \infty}\left(\frac{1}{n} \sum_{i=1}^{n} \bar{\rho}_{i}-\left|\sum_{i=1}^{n} \delta_{i}^{\rho}\right|\right) \\
& =\lim _{n \rightarrow \infty} y_{n} .
\end{aligned}
$$
}


for further analysis. In an important sense, rational expectations of future interest rates are those that are consistent with no opportunities for arbitrage.

\section{Appendix A. The stochastic Discount factor}

We can reformulate our expression of current bond prices as the present value of the adjusted average price in terms of a stochastic discount factor (SDF), which we will denote $M .{ }^{36}$ Since $M$ is stochastic (i.e., random), its value will depend on the outcome of the of the coin flip, either $M^{H}$ or $M^{T}$.

Expectation and covariance. It is convenient to establish some additional notation. Let

$$
E_{0}[x]=\frac{x^{H}+x^{T}}{2}
$$

denote the conditional expectation of $x$. In other words, $E_{0}[x]$ is the average post flip value of $x$ from the perspective of time zero (before the flip). For example, $\bar{p}_{n-1}=E_{0}\left[p_{n-1}\right]$. The conditional expectation has the following property:

$$
E_{0}[a x+b y]=a E_{0}[x]+b E_{0}[y]
$$

where $a$ and $b$ do not depend of the coin flip.

Let

$$
\operatorname{Cov}_{0}[x, y]=\frac{\left(x^{T}-\bar{x}\right)\left(y^{T}-\bar{y}\right)+\left(x^{H}-\bar{x}\right)\left(y^{H}-\bar{y}\right)}{2}
$$

denote the conditional covariance between $x$ and $y$. Covariance measures of how the outcomes of two random variables are related. Here are four ways we can express the conditional covariance in terms of conditional expectations:

$$
\begin{aligned}
\operatorname{Cov}_{0}[x, y] & =E_{0}[(x-\bar{x})(y-\bar{y})] \\
& =E_{0}[(x-\bar{x}) y] \\
& =E_{0}[x(y-\bar{y})] \\
& =E_{0}[x y]-E_{0}[x] E_{0}[y] .
\end{aligned}
$$

Bond pricing with the SDF. We can express the price of a bond in terms of the stochastic discount factor:

$$
p_{n}=E_{0}\left[M p_{n-1}\right] .
$$

The absence of arbitrage opportunities requires the same $M$ be used for all bonds (all assets in fact). The first thing to note is that the price of a one-period bond is simply the average value of the SDF:

$$
p_{1}=E_{0}[M]=\bar{M} \text {. }
$$

Therefore we can write (A.3) as

$$
p_{n}=p_{1} E_{0}\left[\left(\frac{M}{\bar{M}}\right) p_{n-1}\right] .
$$

\footnotetext{
${ }^{36}$ See Cochrane (2000) for an extensive treatment of asset pricing organized around the idea of a stochastic discount factor.
} 
Equation A.4 implies the adjustment parameter (the price of risk) must be embodied in the outcomes of $M / \bar{M}$. Let

$$
M^{H}=(1-\lambda) p_{1} \quad \text { and } \quad M^{T}=(1+\lambda) p_{1} .
$$

Note that the volatility of $M$ is

$$
\frac{M^{H}-M^{T}}{2}=-\lambda p_{1} .
$$

We see that the stochastic discount factor can be constructed from the risk-free return and the price of risk.

Using (A.1) and (A.2), we can write the right-hand side of (A.3) as

$$
E_{0}\left[M p_{n-1}\right]=\bar{M} E_{0}\left[\left(\frac{M}{\bar{M}}\right) p_{n-1}\right]=\bar{M}\left(\bar{p}_{n-1}+\operatorname{Cov}_{0}\left[\left(\frac{M}{\bar{M}}\right), p_{n-1}\right]\right)
$$

which implies

$$
\frac{\bar{p}_{n-1}}{p_{n}}=\frac{1}{\bar{M}}-\operatorname{Cov}_{0}\left[\left(\frac{M}{\bar{M}}\right),\left(\frac{p_{n-1}}{p_{n}}\right)\right] .
$$

Equation (A.5) says that the expected one-period (gross) return on a bond equals the inverse of the average stochastic discount factor minus a term that depends on the covariance of the return with the stochastic discount factor.

Note that

$$
\operatorname{Cov}_{0}\left[\left(\frac{M}{\bar{M}}\right),\left(\frac{p_{n-1}}{p_{n}}\right)\right]=E_{0}\left[\left(\frac{M}{\bar{M}}-1\right)\left(\frac{p_{n-1}}{p_{n}}\right)\right]=-\lambda \frac{\delta_{n-1}^{p}}{p_{n}} .
$$

The risk premium is seen to be a covariance. Our simple setting makes it seem as though the only way for a risky bond to have no premium is for the price of risk to be zero. But in a more general setting where there is more than one source of uncertainty (two coins, for example, shifting bond prices of different maturities in two different ways) it is possible for a risky bond to have no risk premium even though the price of risk is not zero. See Appendix C.

\section{Appendix B. Adjusted probabilities}

In order to account for how investors feel about the kind of risk they face, we have used the adjusted average price. It turns out that we can express the adjusted average price in terms of adjusted probabilities, where the price of risk is used as an adjustment parameter.

The true probabilities of heads and tails are $\left(\frac{1}{2}, \frac{1}{2}\right)$. We can adjust the probabilities to make the average either higher or lower. Let $(q, 1-q)$ denote the adjusted probabilities. We can write the adjusted probabilities in terms of the adjustment parameter $\lambda$ :

$$
(q, 1-q)=\left(\frac{1-\lambda}{2}, \frac{1+\lambda}{2}\right) \quad-1<\lambda<1
$$

The adjusted probabilities add up to one by construction, and as long as $\lambda$ is less than one in absolute value, the adjusted probabilities will both be positive. If $\lambda=0$, then there is no adjustment and the adjusted probabilities equal the 
true probabilities. We can compute an adjusted average price using the adjusted probabilities:

$$
\begin{aligned}
q p_{n-1}^{H}+(1-q) p_{n-1}^{T} & =\left(\frac{1-\lambda}{2}\right) p_{n-1}^{H}+\left(\frac{1+\lambda}{2}\right) p_{n-1}^{T} \\
& =\bar{p}_{n-1}-\lambda \delta_{n-1}^{p} .
\end{aligned}
$$

Equation (B.1) shows the relation between the adjusted average price and the true average price. ${ }^{37}$ The difference between the two is the product of the adjustment parameter and the volatility of the bond price.

Returning to (B.1), we see that if $\lambda=0$ the adjusted average price would equal the true average price. But suppose $\lambda<0$. Would the adjusted average price be greater than or less than the true average price? The answer depends on whether the volatility is positive or negative. Thus far we have not said whether the price of a bond will be higher if the coin comes up heads or if it comes up tails (i.e., whether $\delta_{n-1}^{p}$ is positive or negative). Once we make that choice, we will know how to set $\lambda$ to make the necessary adjustment. For example, suppose that (1) the volatility of bond prices is negative and (2) the risk from holding bonds is a "bad" risk (i.e., it increases the overall uncertainty of investors' lives). In this case, the adjustment parameter should be negative in order to make the adjusted average price less than the true average price, thereby raising the average return above the risk-free rate.

\section{Appendix C. Two sources of unCERTAinty}

In this appendix we see how to satisfy the strong form of the expectations hypothesis when there are two sources of uncertainty. ${ }^{38}$ With two sources of uncertainty, we can use the risk-premium to exactly cancel the convexity effect.

There will be two independent coin flips, each with a probabilities of $\left(\frac{1}{2}, \frac{1}{2}\right)$ for heads and tails. The four possible outcomes for the price of an $n$-period bond next period when it becomes an $(n-1)$-period bond are given in Table 21. Each outcome has of probability of $\frac{1}{4}$ of occuring. The average value is $\bar{p}_{n-1}$ and the variance is

$$
\left(\delta_{1, n-1}^{p}\right)^{2}+\left(\delta_{2, n-1}^{p}\right)^{2}
$$

TABLE 21. The price of a bond next period depends on the outcomes of two coin flips.

\begin{tabular}{lccc}
\hline \hline & \multicolumn{1}{c}{ Heads } & & Tails \\
\cline { 2 - 2 } Heads & $p_{n-1}^{H H}=\bar{p}_{n-1}+\delta_{1, n-1}^{p}+\delta_{2, n-1}^{p}$ & & $p_{n-1}^{H T}=\bar{p}_{n-1}+\delta_{1, n-1}^{p}-\delta_{2, n-1}^{p}$ \\
Tails & $p_{n-1}^{T H}=\bar{p}_{n-1}-\delta_{1, n-1}^{p}+\delta_{2, n-1}^{p}$ & & $p_{n-1}^{T T}=\bar{p}_{n-1}-\delta_{1, n-1}^{p}-\delta_{2, n-1}^{p}$ \\
\hline \hline
\end{tabular}

\footnotetext{
${ }^{37}$ The adjusted average price is sometimes referred to as a certainty equivalent.

${ }^{38}$ See McCulloch (1993) and Fisher and Gilles (1998).
} 
Each coin flip will have adjusted probabilities ${ }^{39}$ and its own adjustment parameter to account for how investors feel about the uncertainty of each of the two flips (it could be the case that one coin flip is good risk while the other is bad):

$$
\left(q_{i}, 1-q_{i}\right)=\left(\frac{1-\lambda_{i}}{2}, \frac{1+\lambda_{i}}{2}\right) \quad \text { for } i=1,2 .
$$

The adjusted probabilities of each of the four outcomes is shown in Table 22 .

TABLE 22. The adjusted probabilities of each of the outcomes of two coin flips.

\begin{tabular}{lclc}
\hline \hline & Heads & & Tails \\
\cline { 2 - 2 } Heads & $q_{1} q_{2}$ & & $q_{1}\left(1-q_{2}\right)$ \\
Tails & $\left(1-q_{1}\right) q_{2}$ & & $\left(1-q_{1}\right)\left(1-q_{2}\right)$ \\
\hline \hline
\end{tabular}

Combining Tables 21 and 22 and Equation (C.1), we can write the adjusted average price of an $(n-1)$-period bond as

$$
\bar{p}_{n-1}-\lambda_{1} \delta_{1, n-1}^{p}-\lambda_{2} \delta_{2, n-1}^{p} .
$$

We can solve for the expected return:

$$
\frac{\bar{p}_{n-1}-p_{n}}{p_{n}}=r+\lambda_{1} \sigma_{1, n-1}+\lambda_{2} \sigma_{2, n-1} .
$$

We see that the risk premium is composed of two parts, one for each source of risk. ${ }^{40}$

With two sources of risk, we cannot construct a risk-free portfolio from two bonds; but we can construct one using three bonds with maturities of $n$-periods, $m$-periods, and $\ell$-periods. The post-flip value of the portfolio is shown in Table 23. We can find the portfolio weights that make the portfolio risk-free by solving the following two equations for $b$ and $c$ :

$$
\pi^{H H}=\pi^{H T} \quad \text { and } \quad \pi^{H T}=\pi^{T T} .
$$

The solution is

$$
b=\frac{\delta_{2, \ell-1}^{p} \delta_{1, n-1}^{p}-\delta_{1, \ell-1}^{p} \delta_{2, n-1}^{p}}{\delta_{1, \ell-1}^{p} \delta_{2, m-1}^{p}-\delta_{2, \ell-1}^{p} \delta_{1, m-1}^{p}} \quad \text { and } \quad c=\frac{\delta_{2, m-1}^{p} \delta_{1, n-1}^{p}-\delta_{1, m-1}^{p} \delta_{2, n-1}^{p}}{\delta_{2, \ell-1}^{p} \delta_{1, m-1}^{p}-\delta_{1, \ell-1}^{p} \delta_{2, m-1}^{p}} .
$$

A risk-free portfolio must earn a risk-free return or else there will be arbitrage opportunities. This condition requires that each of the two adjustment parameters, $\lambda_{1}$ and $\lambda_{2}$, must be the same across all three bonds in order to guarantee the absence of arbitrage. Hence we will refer to $\lambda_{1}$ and $\lambda_{2}$ as (the two components of) the market price of risk.

\footnotetext{
${ }^{39}$ Adjusted probabilities are discussed in Appendix B.

${ }^{40}$ Note that if $\lambda_{1} / \lambda_{2}=-\sigma_{2, n-1} / \sigma_{1, n-1}$, the risk premium will be zero even though there is risk and the price of risk is not zero.
} 
TABLE 23. The value of the portfolio after the two coin flips.

\begin{tabular}{lccc}
\hline \hline & Heads & & Tails \\
\cline { 2 - 3 } Heads & $\pi^{H H}=p_{n-1}^{H H}+b p_{m-1}^{H H}+c p_{\ell-1}^{H H}$ & & $\pi^{H T}=p_{n-1}^{H T}+b p_{m-1}^{H T}+c p_{\ell-1}^{H T}$ \\
Tails & $\pi^{T H}=p_{n-1}^{T H}+b p_{m-1}^{T H}+c p_{\ell-1}^{T H}$ & & $\pi^{T T}=p_{n-1}^{T T}+b p_{m-1}^{T T}+c p_{\ell-1}^{T T}$ \\
\hline \hline
\end{tabular}

We can write the yield on an $n$-period bond at time zero as

$$
y_{n}=\frac{1}{n}\left(y_{1}+(n-1) \bar{y}_{n-1}\right)-\frac{1}{n} \mathcal{P},
$$

where $\mathcal{P}$ is the risk-related term premium,

$$
\mathcal{P}=\log \left(\cosh \left(x_{1}\right) \cosh \left(x_{2}\right)+\lambda_{1} \sinh \left(x_{1}\right) \cosh \left(x_{2}\right)+\lambda_{2} \sinh \left(x_{2}\right) \cosh \left(x_{1}\right)\right),
$$

and $x_{j}=(n-1) \delta_{j, n-1}^{y}$. Although the risk-related premium is more convoluted when there are two coin flips than when there is only one, its basic features remain the same as the following approximations show. First, if the price of risk is zero $\left(\lambda_{1}=\lambda_{2}=0\right)$, then we can approximate the convexity part by

$$
\log \left(\cosh \left(x_{1}\right) \cosh \left(x_{2}\right)\right) \approx \frac{1}{2}\left(x_{1}^{2}+x_{2}^{2}\right),
$$

which depends on the variance of the $(n-1)$-period bond. Second, we can approximate the risk premium by

$$
\log \left(1+\lambda_{1} \sinh \left(x_{1}\right) \cosh \left(x_{2}\right)+\lambda_{2} \sinh \left(x_{2}\right) \cosh \left(x_{1}\right)\right) \approx \lambda_{1} x_{1}+\lambda_{2} x_{2} .
$$

We can write the yield in terms of the interest rate forecasts and volatilities: $y_{n}=\frac{1}{n} \sum_{i=1}^{n} \bar{\rho}_{i}-\frac{1}{n} \mathcal{P}$, where $x_{j}=(n-1) \delta_{j, n-1}^{y}=s_{j, n}=\sum_{i=1}^{n} \delta_{j, i}^{\rho}$. The strong form of the expectations hypothesis implies

$$
\begin{aligned}
& \cosh \left(s_{1, n}\right) \cosh \left(s_{2, n}\right)+ \\
& \lambda_{1} \sinh \left(s_{1, n}\right) \cosh \left(s_{2, n}\right)+\lambda_{2} \sinh \left(s_{2, n}\right) \cosh \left(s_{1, n}\right)=1 .
\end{aligned}
$$

Equation (C.2) can be solved for non-zero $\delta_{j, n}^{\rho}$ given $\lambda_{j}$. For example, if $\lambda_{1}=0$ and $\lambda_{2}=1$, then we can choose any sequence of $s_{1, n}$ as long as we set $s_{2, n}=$ $-\log \left(\cosh \left(s_{1, n}\right)\right)$.

We have shown that it is possible to satisfy the strong form of the expectations hypothesis. This does not mean, however, that it is correct. In fact, it is not.

\section{REFERENCES}

Black, F. and M. Scholes (1973). The pricing of options and corporate liabilities. Journal of Political Economy 81, 637-654.

Campbell, J. Y. (1986). A defense of traditional hypotheses about the term structure of interest rates. Journal of Finance 41, 183-193.

Cochrane, J. H. (2000). Asset pricing. Currently available on the web at http://gsb-www. uchicago.edu/fac/john. cochrane/research/Papers/. 
Cox, J. C., J. E. Ingersoll, Jr., and S. A. Ross (1981). A reexamination of traditional hypotheses about the term structure of interest rates. Journal of Finance 36, 769-799.

Dybvig, P. H., J. E. Ingersoll, and S. A. Ross (1996). Long forward and zerocoupon rates can never fall. Journal of Business 69(1), 1-25.

Fisher, M. (2001). Forces that shape the yield curve. Federal Reserve Bank of Atlanta Economic Review 86(1), 1-15.

Fisher, M. and C. Gilles (1998). Around and around: The expectations hypothesis. Journal of Finance 53, 365-383.

McCulloch, J. H. (1993). A reexamination of traditional hypotheses about the term structure of interest rates: A comment. Journal of Finance 48(2), 779789.

Vasicek, O. (1977). An equilibrium characterization of the term structure. Journal of Financial Economics 5, 177-188.

Research Department, Federal Reserve Bank of Atlanta, 104 Marietta St., AtLANTA, GA 30303

E-mail address: mark.fisher@atl.frb.org 